CHANGE CHAMPIONS FOR STUDENT RECRUITMENT: LEADER

EXPERIENCES IN MANAGING CHANGE FOR NEW TECHNOLOGY ADOPTION

A Dissertation

Presented to

the Faculty of the Graduate School

at the University of Missouri

In Partial Fulfillment

of the Requirements for the Degree

Doctor of Education

by

P. SUZANNE SHARP

Dr. Jennifer Hart, Dissertation Supervisor

MAY 2018 
The undersigned, appointed by the Associate Vice Chancellor of the Office of Research and Graduate Studies, have examined the dissertation entitled

\section{CHANGE CHAMPIONS FOR STUDENT RECRUITMENT: LEADER EXPERIENCES IN MANAGING CHANGE FOR NEW TECHNOLOGY ADOPTION}

presented by P. Suzanne Sharp,

a candidate for the degree of doctor of education,

and hereby certify that, in their opinion, it is worthy of acceptance.

Dr. Jennifer Hart, Advisor

Dr. Jennifer Fellabum-Toston

Dr. Casandra Harper Morris

Dr. Danna Wren 


\section{ACKNOWLEDGEMENTS}

This has been a rewarding journey and I am grateful for the support and encouragement of those who helped me achieve this life goal. I would first like to thank the faculty and administrators who make the statewide cohort program possible. The cohort experience allowed me to keep moving forward with a group of colleagues offering diverse perspective and a shared passion for education.

I am especially appreciative of my advisor, Dr. Jeni Hart, who added me to her list of advisees with little knowledge of me or my research interest. After my first meeting with her, I knew I had found the advisor who would provide the guidance, insight, and support to help get to the finish line. She accepted a new position in the graduate school shortly after this initial meeting yet remained committed to seeing me through. Dr. Hart was patient, encouraging, and always looked out for my best interest. I would also like to thank the members of my committee and acknowledge their support. Dr. Casandra Harper Morris was part of the faculty involved with our cohort early on and has been a consistent presence for me in the ELPA program. Dr. Fellabaum-Toston also helped me in earlier stages when I attended her dissertation boot camp. Finally, Dr. Danna Wren provided a valuable perspective as an administrator who works with technology. Please know how much I appreciate what all of you do to help students achieve their educational goals.

My family has been extremely supportive of this endeavor. I'd like to thank my husband, who continually asked what he could do help, and also kept pushing me to "get it done." My daughter has been an inspiration as she demonstrates her own commitment to learning and school. I am fortunate to have other family who also supported my 
journey, including parents, in-laws, aunts and uncles. They are amazing role models who show me that anything is possible if you make a commitment and stick to it.

I would like to thank Liaison International, the company for which I work, for their commitment to higher education and support of all employees pursuing degrees. Finally, I would like to acknowledge and thank the enrollment professionals who agreed to participate in my study. All were busy leaders who took time to share their leadership insight, making this study possible. 


\section{TABLE OF CONTENTS}

ACKNOWLEDGEMENTS

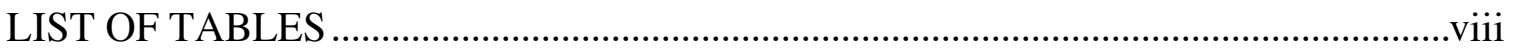

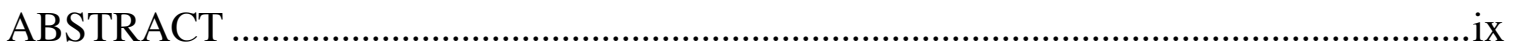

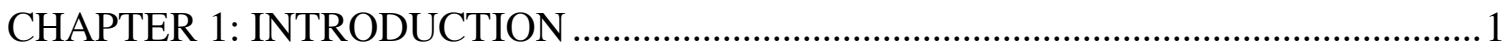

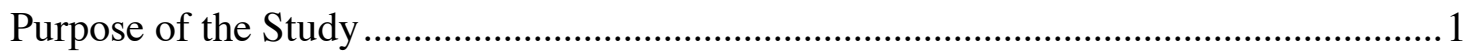

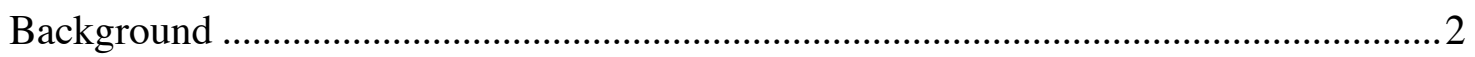

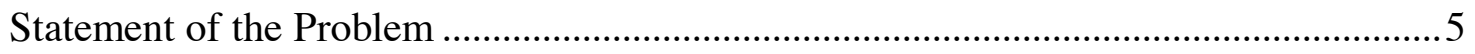

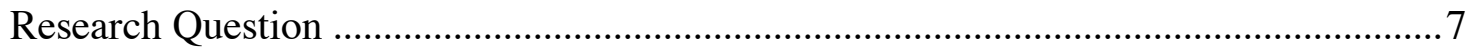

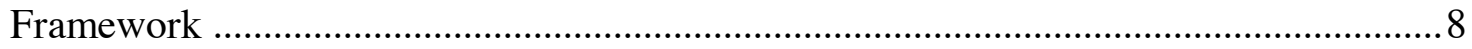

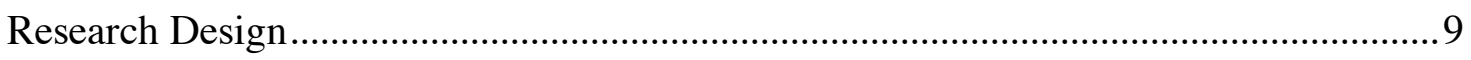

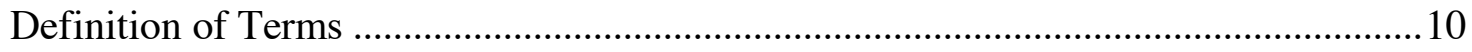

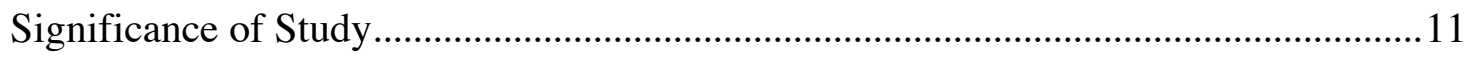

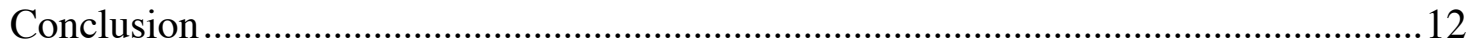

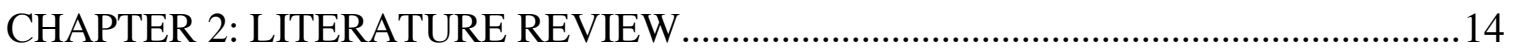

Enrollment Management and Leadership ............................................................. 14

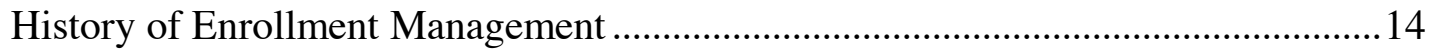

Enrollment Management Leaders and Their Stakeholders ........................................18

CRM Adoption, Technology, and Student Recruitment ...........................................22

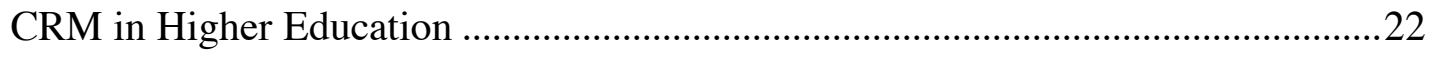


Student Expectations and Technology

Summary of Enrollment Management, CRM, and Technology ..................................26

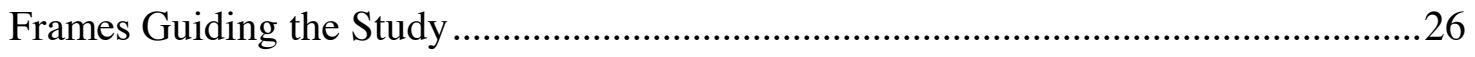

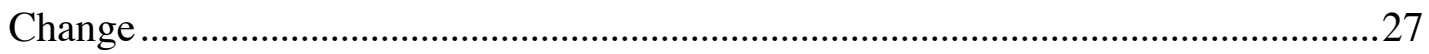

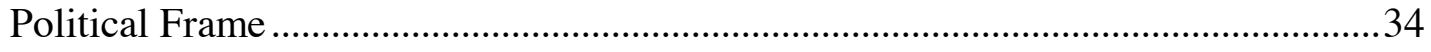

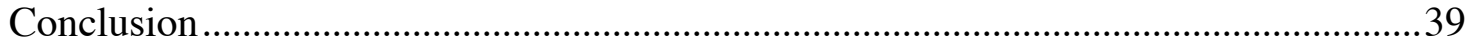

CHAPTER 3: METHODOLOGY AND RESEARCH DESIGN ...................................40

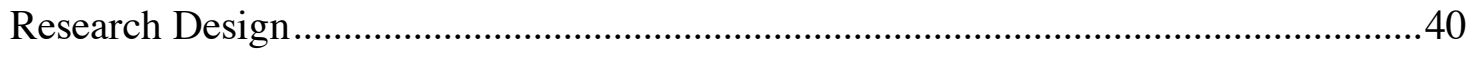

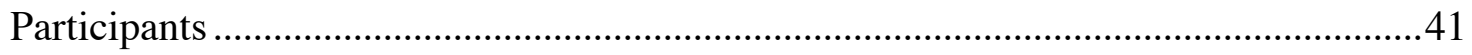

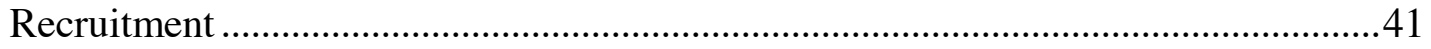

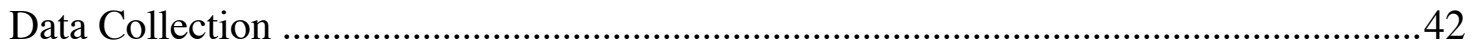

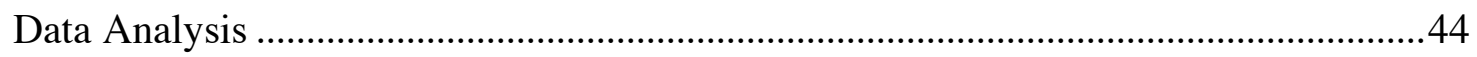

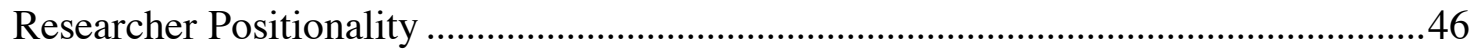

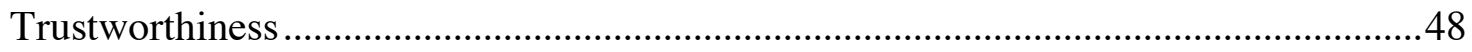

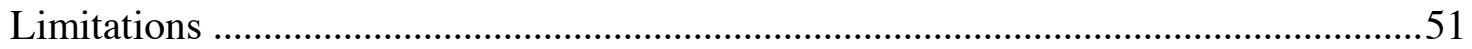

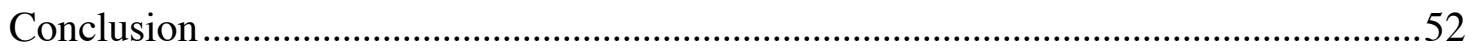

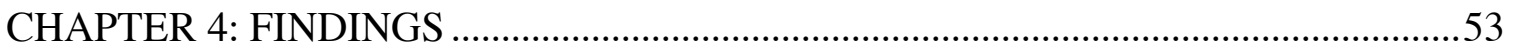

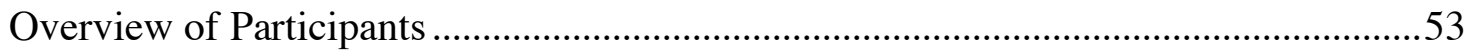

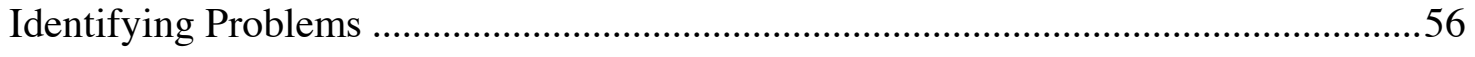

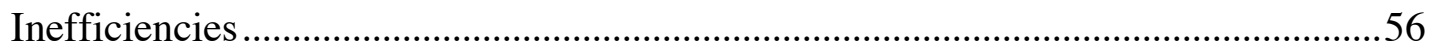


Ineffective Communication

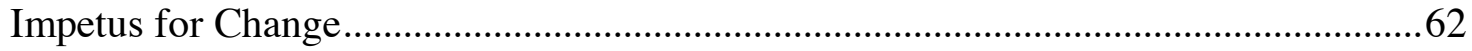

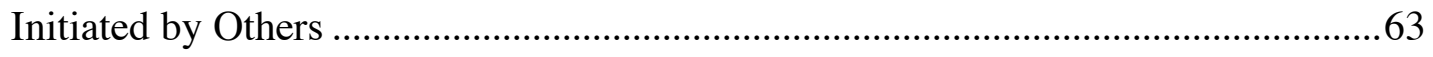

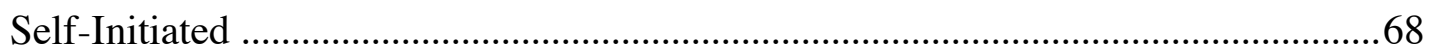

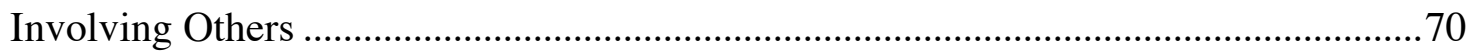

Reaching Outside Their Institution ..................................................................... 71

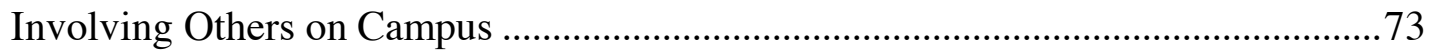

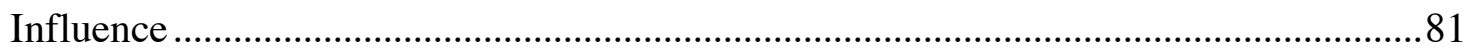

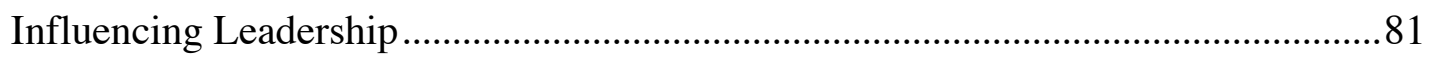

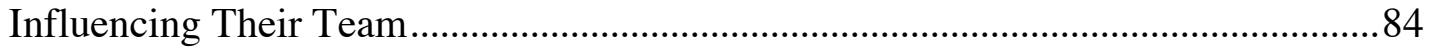

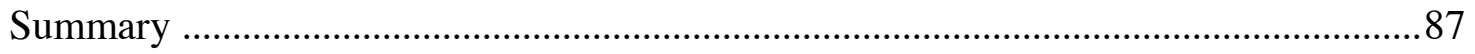

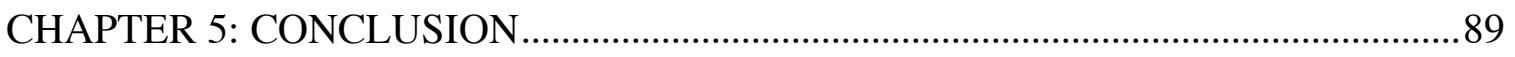

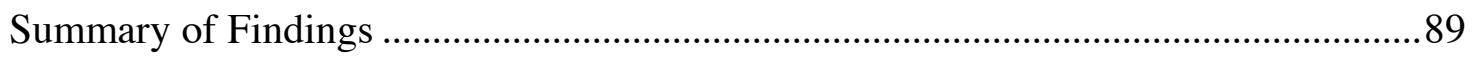

Participants and Role in Enrollment Management ................................................90

Technology for Student Recruitment ................................................................. 90

Establishing Urgency and Creating Coalitions ...................................................... 92

Establishing and Maintaining Urgency ….......................................................... 92

Creating Coalitions: No One Does It Alone ...........................................................94

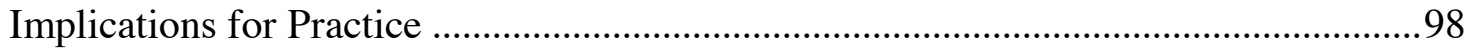

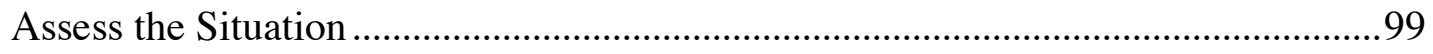




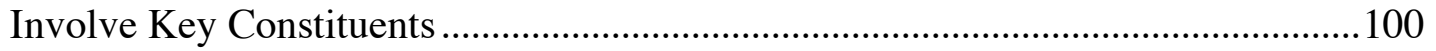

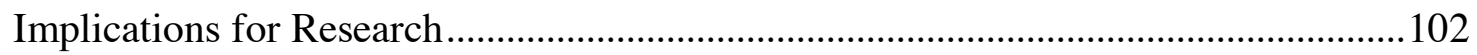

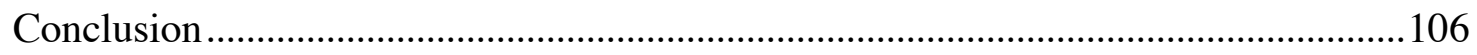

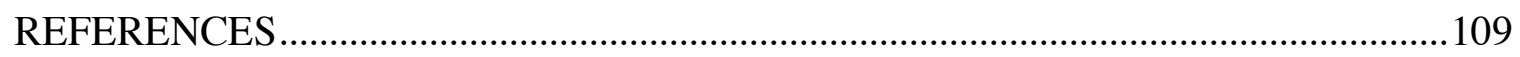

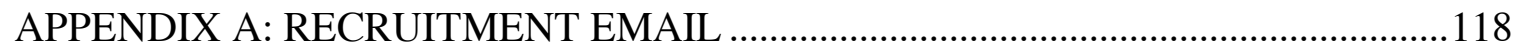

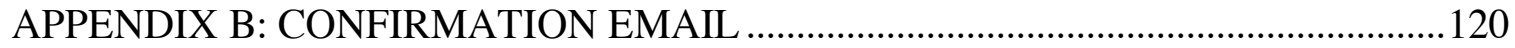

APPENDIX C: IRB LETTER AND INFORMED CONSENT ......................................121

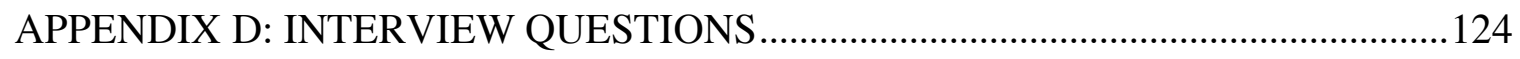

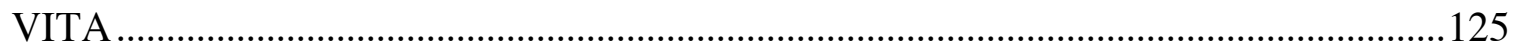




\section{LIST OF TABLES}

Table

Page

Participant Information................................................... 55

Who Participants Involved and When............................................ 71 


\begin{abstract}
Small, private, primarily undergraduate colleges and universities have been facing challenges in enrollment as number of traditional-aged college students declines and options for obtaining a degree expand. In response, schools often seek out and adopt new technology to improve their student recruitment functions. Existing research largely focuses on the technical aspects of adoption but does not provide much insight into the process of leading change itself. The purpose of this study was to understand the experience of higher education leaders in championing change through adoption of new technology for student recruitment. I interviewed 12 enrollment management leaders in higher education about their experiences guiding the technology adoption process on their campus. All participants were at small, private, primarily undergraduate institutions. This qualitative case study focused on the common phenomenon experienced by the participants - being the champion for selecting and purchasing new technology. Early stages of change management (Kotter, 2012) served as the framework for my research. In addition, I relied on a secondary framework, Bolman and Deal's (2008) political frame, to provide further insight about the participants' experiences. Four themes emerged from the findings: identifying problems, impetus for change, involving others, and influence. This study concludes that managing change itself is a significant aspect of the process. Based on the findings I offer recommendations for practice and identify opportunities for further research.
\end{abstract}




\section{CHAPTER 1: INTRODUCTION}

In 2005, Kotter and Rathgeber wrote a fable to explain Kotter's (1996) eight stages of change management. The fable, entitled "Our Iceberg is Melting” (Kotter \& Rathgeber, 2005) introduced a penguin named Fred, who in many ways, resembles leaders in higher education enrollment management today. Fred is part of a colony of penguins living on an iceberg he discovers is melting and putting the colony at risk. As Fred recognizes this impending danger, he must use Kotter's eight stages of change management to help the entire colony move to safety. Much as the colony of penguins in this tale needed a solid and stable iceberg on which to live, institutions of higher education must have a solid enrollment "iceberg" to survive and thrive. When leaders responsible for managing enrollment on these campuses recognize threats to enrollment, they need to lead the change process for their campus to take action, and avoid becoming a melting iceberg.

\section{Purpose of the Study}

The purpose of this case study was to understand experiences of enrollment management leaders who have led the process of selecting new technology specifically for undergraduate student recruitment. I wanted to understand two phases of the process: 1) the decision to adopt new technology, and 2) choosing among multiple vendors who supply the technology. At the same time, I reflected on the role of change and political context in which these processes occur:

The participants in my study specifically selected the following technology: The Enrollment Marketing Platform (EMP). My own experience as a former vice president of enrollment management who selected this specific technology inspired this study. From 
my own experience, and talking with other leaders considering the EMP, we found ourselves managing change with different constituencies on our campuses as we selected the EMP. This experience reinforced for me the role campus politics and change management played.

For this study, I was interested in leaders at smaller colleges and universities, not unlike the college in which I worked as a vice president of enrollment management. Specifically, the pressure on them tends to be greater for success in student recruitment (Carlson, Blumenstyk, \& Thomason, 2015). I wondered whether these enrollment management leaders who selected the EMP experienced similar challenges to me. I currently work with the company who provides the solution, giving me unique access to potential participants. The company provided me with contact information of current clients who experienced the phenomenon under investigation to participate in my study, which facilitated my ability to conduct this research.

\section{Background}

Higher education in the U.S. has experienced an array of challenges over the years, including post-World War II enrollment growth and the need for expansion, and shifts in non-traditional student growth and new methods of course delivery (Thornton, 2016). More recent challenges facing higher education include new technological advances, an increased global society, strained race relations, economic disparities and inequities, materialism, deteriorating infrastructures, more colleges competing for fewer traditional-aged students, regulations imposed upon the government related to education and funding, and increased public scrutiny (Astin \& Astin, 2000; Davis, 2003; Keller, 2004; Thornton, 2016). These concerns fit into three overarching and related challenges 
currently facing higher education: 1) declining revenue, 2) demographic shifts; and, 3) technology transformations (Thornton, 2016).

Revenue challenges are often a direct result of lower enrollment, especially for smaller, private schools that rely on tuition as a major source of revenue (Carlson, 2014; Dalton \& Somers, 2015). However, as state appropriations for public colleges and universities decrease, they are also forced to rely more on tuition and other revenue streams (Heller, 2006; Priest \& St. John, 2006). As schools become more dependent on tuition, the enrollment management function becomes increasingly important, and not without challenges. Related to revenue shortfalls is the aforementioned decline in students aged 18-24 due to the United States' demographic shifts (National Student Clearinghouse, 2015; Thornton, 2016), leading to increased competition among colleges and universities to recruit and enroll these students. In addition, technology has changed the expectations of these prospective students (Lindbeck \& Fodrey, 2010), often presenting additional hurdles for colleges and universities to recruit these students, using the "high tech" strategies to which they have come to expect.

Although the outlook for college finances was recently upgraded from "negative" to "stable," the outlook is still not good (Thomason, 2015). A survey of 368 colleges in 2014 revealed 38\% had not met enrollment and net tuition revenue goals (Carlson, Blumenstyk, \& Thomason, 2015). The situation is even worse for smaller, private colleges, according to a survey conducted by the Council on Independent Colleges (CIC) and the American Association of State Colleges and Universities (AASCU). Nearly half of the private colleges reported not meeting their enrollment and/or net tuition goals (Carlson et al., 2015). These private schools tended to have fewer than 1,500 students. 
However, public institutions were not immune to these issues (Freidrich, 2015). The public institutions most affected by unmet tuition revenue goals were those that enroll fewer than 5,000 students.

Enrollment is key for many colleges to survive and thrive. As enrollment declines, budgets are often cut, and resources become scarce (Carlson, 2014). Even institutions with state funding find themselves becoming more tuition dependent with state budgets being slashed (Heller, 2006; Priest \& St. John, 2006). Across the majority of campuses, enrollment predictions are a large variable in budgeting projected revenue (Langston, Wyant, \& Scheid, 2016). Colleges depend on enrollment tuition for many functions on campus, including services to students, faculty and staff salaries, and other resources to maintain a campus. Further, declining enrollment results in declining resources across nearly all areas of an institution. Carlson reported a high number of schools had not met their revenue and enrollment goals and asked leaders at these schools how they planned to respond. About $20 \%$ of the leaders indicated that the institution would offer early retirement, furloughs, and layoffs in 2014-2015, up from 14-16\% in 2013-2014 (Carlson, 2014). In addition to those strategies, both AASCU and CIC schools indicated that improving enrollment management operations and putting more resources into marketing were among the highest priorities (Carlson, 2014).

Leadership at the board level is ultimately responsible for the fate of small colleges and governing boards need to pay attention to the leadership on a college campus (Wootton, 2016). The president is ultimately responsible to the board, but leaders in enrollment management are often the key player on a campus (Stewart, 2004), responsible for recruiting and retaining students paying tuition dollars to fund the 
institution. Declining enrollments at small, 4-year colleges call for change management in marketing, recruiting, and retaining new students.

Despite their critical leadership role, enrollment managers often have limited power and authority (Stewart, 2004). Enrollment managers must appeal to multiple constituents across a college campus, calling for them to facilitate competing priorities, often with limited financial resources (Stewart, 2004). This facilitation can entail negotiating with teams, peers, executive level leaders, college presidents, and governing boards, and is often highly political. Politics run deep on a college campus (Bolman \& Gallos, 2011) and higher education is not known for swift change, complicating the work of enrollment managers in a time when the ability to be nimble is critical.

\section{Statement of the Problem}

As the number of potential college students between the ages 18-24 declines in the United States (National Student Clearinghouse, 2015; Thornton, 2016), colleges and universities find themselves competing for fewer students in that age group. As a result, some colleges are at risk of closing due to low enrollment, especially at institutions with smaller endowments and challenges with fundraising. Colleges that typically rely on tuition revenue are, in some cases, supplementing their budgets by decreasing the principles of already small endowment funds (Anderson, 2015; Belkin, 2013; Berman, 2015; Blumenstyk, 2015). One such school that has been highly publicized is Sweet Briar College in Virginia.

In March of 2015, campus leaders at Sweet Briar announced the college would be closing. This announcement sparked protests by alumnae and supporters. By July, Sweet Briar decided to keep the college open with virtually all new campus leadership and 
board members (Stripling, 2015). Although Sweet Briar did not close, its future remains tenuous, as are the futures of many more colleges. Some predict that as many as $50 \%$ of colleges may close or merge by 2020 (Dennis, 2014) and the 2016 State of Higher Education Report speculates there "may be as many as 100 Sweet Briars in the making" (Thornton, 2016, p. 4). Like Sweet Briar, campuses often reimagine enrollment strategies to avoid closing their doors, melting as Fred's iceberg in the fable.

Many colleges, like those mentioned previously, are in trouble and know it, but a number of them are not talking about it yet. Numbers (e.g., yield, applications, enrollment, and financial assets) are trending downward and boards, presidents, lenders, and accreditors are all concerned (Thornton, 2016). The importance of enrollment strategies will increase as colleges recognize the reality of their situation and the implication for sustaining the institution (Thornton, 2016). Colleges and universities are now spending millions of dollars on recruitment (Fisk, 2008) in the hope of attracting students to their institution. As part of recruitment, enrollment management leaders must develop creative strategies, combined with new technology, to grab the attention of today's students; they are also expected to be able to understand and use technological advances and advocate for limited resources (Stewart, 2004).

In order to compete for students, many colleges and universities are investing in new technology to automate and personalize their outreach, using multiple channels to adapt to today's traditional-aged prospective student (Belkin, 2013; Fiske, 2008). The prospective student today never knew the world without real-time, highly-connective technology (Lindbeck \& Fodrey, 2009). Although recruitment will always involve engaging and forming relationships with prospective students, the use of technology has 
become an essential tool for colleges and universities to reach students in their own space. It is estimated that nearly $50 \%$ of colleges and universities now incorporate erecruiting strategies using mobile phones and web pages (Lindbeck \& Fodrey, 2009). It is evident enrollment management leaders are adopting new technology to enhance efforts for recruitment (Lindbeck \& Fodrey, 2010), yet there is little research on the process by which any leader identifies the need for change, creates urgency, and forms coalitions to make the change happen.

As enrollment leaders tackle the challenges of marketing and recruitment on their campuses and strive to integrate new technology, we empirically understand very little about their efforts. In light of the increasing scrutiny on enrollment management leaders at a time for diminishing resources and increased use of technology, I am particularly interested in understanding the experience of enrollment leaders who have successfully championed the decision to purchase and implement a new solution, changing their core process of marketing and recruiting students. Understanding the experience of successfully advocating for new technology to enhance student recruitment, within the political climate of U.S. institutions of higher education, may help other leaders more effectively influence similar change on their campus.

\section{Research Question}

The research question guiding this study was: How do enrollment management leaders at small, private, primarily undergraduate colleges describe their experience establishing urgency and creating coalitions as they led the selection process to adopt the EMP technology for the primary purpose of recruiting students? 


\section{Framework}

The selection process to adopt the EMP technology specifically involves participants' initiating a change and navigating politics within their organization (Bolman \& Deal, 2008; Bolman \& Gallos, 2011). As a result, I framed this study using Kotter's (2012) first two stages of change management. Kotter's (2012) first two stages of change management are establishing urgency and creating a guiding coalition. These stages relate directly to politics and the process by which leaders understand and navigate the political terrain on their campus. Kotter's other stages of change management could have been considered; however, my focus was on how leaders described their experience toward the beginning of the adoption, which primarily includes the stages of creating urgency and forming coalitions and does not involve the latter stages. In addition, the intent was to understand this phenomenon as the participants' personal experience, thus a narrower frame allowed for more depth. Yet, I recognize that relying on the first two stages of Kotter's model may mean that other important elements of the overall essence may be missed.

Coalition building is wrought with organizational politics (Bolman \& Deal, 2008). Thus, the political frame provided an additional lens to recognize sources of power, conflict, and decision making. These are important to enrollment management leaders as they strive to have their campus adopt the EMP. Key sources of power include position power, control of rewards, coercive power, expertise, personal power, alliances and networks, and access and control of agendas (Bolman \& Deal, 2008; French \& Raven, 2005). Such sources of power are only relevant within relationships among participants, called actors. These actors may be individuals, subunits, or organizations that have more 
or less power in relation to other actors (Pfeffer, 2005). As participants described their experience, the political frame helped me understand how these leaders worked with others on campus, how they understood the other players (or actors or social agents), mapped the terrain, and responded accordingly. It is important for leaders to not only be aware of the actors/social agents with whom they work, but to truly understand the influence each has within the organization in regard to successful change management.

Politics exist within organizations and must be recognized as a force that can help or hinder change (Bolman \& Deal, 2008). An important component to managing change effectively is successfully navigating politics (Kezar, 2014). Politics are prevalent in every organization (Bolman \& Deal, 2008; Bolman \& Gallos, 2011) and the savvy leader understands and embraces this by mapping the political terrain, gaining insight into other's views, and becoming influential (Kezar, 2014). Leaders who are able to learn, understand, and exercise these skills will be more successful in influencing change within their organization (Bolman \& Deal, 2008).

\section{Research Design}

I believe knowledge is socially constructed, thus selecting a qualitative methodology was an appropriate approach. The social constructivist paradigm guides the search for meaning in how participants experienced a specific process or phenomenon (Creswell, 2009), in this case, the selection of the EMP. This viewpoint was appropriate

for my research as I was striving to rely as much as possible on the participant's view of their experience and how they described it. I conducted a case study to answer my research questions, using qualitative techniques informed by Creswell $(2007,2009)$, Merriam (2009), and Yin (2014). 
The primary form of data collection for this study was semi-structured, in-depth individual interviews. This approach was a good fit for my study as I wanted the participants to tell a story in their own words and capture the collective essence of their experience (Smith et al., 2009). I interviewed a total of 17 participants using GoToMeeting with both video and audio. Participants were all enrollment management leaders at institutions of small colleges or universities who recently (within the last 2.5 years) led the process of purchasing and implementing the EMP to improve student recruitment. Approximately 16 small, private, primarily undergraduate colleges have adopted the EMP in the last 2.5 years.

\section{Definition of Terms}

This study focused on the collective experience of leaders in enrollment management at small colleges who recently decided to purchase a specific $\mathrm{CRM} /$ marketing platform, specifically the EMP. Within these experiences, there are many terms that warrant definition. Next, I define common terms used throughout the study to help clarify meaning and intent for readers. I will further define and discuss each of these throughout the study.

Admissions - The process of admitting or allowing students to enter a college and/or program to earn a degree.

Customer Relationship Management (CRM) - A CRM is a software solution system to help an organization manage relationships with customers. Higher education has not always considered their students "customers," and this continues to be a point of some debate. However, CRM is a more recent term regularly used to reference student 
services and recruitment (Bejou, 2005; Guilbault, 2016; Lewison \& Hawes, 2007; Rigo, Pedron, Caldeira, \& Araujo, 2016; Schultz \& Lucido, 2011).

Enrollment Marketing Platform (EMP) - A software solution designed for college recruitment that bundles a marketing platform and CRM functions. EMP is a specific solution owned by Liaison.

Enrollment Management - The process by which a college recruits and retains students. For the purpose of this study, the focus is on recruitment.

Recruitment - The function of attracting students to apply and enroll at a specific college.

Small School - A college serving fewer than 5,000 students (Carlson, 2015).

\section{Significance of Study}

This study is significant to professionals in higher education in several ways.

First, the results of this study help fill a gap in understanding an increasingly common experience for leaders in enrollment management. The primary focus of any initiative in enrollment management is on numbers. It is the reason new solutions are sought out and adopted - to influence the final enrollment number (Carlson, 2014; Fiske, 2008).

Although the focus on results is critical for schools, we overlook the experience these leaders have in making a large decision to support their school and how they must work across campus departments to facilitate change efforts. The results of the study are not only relevant to leaders in enrollment management, but may also provide valuable insight for other leaders in higher education.

Enrollment on college campuses is more likely than ever to impact budgeting and revenue projections (Langston, Wyant, \& Scheid, 2016), and thus, is a key concern for 
top leadership and executive teams, including the chief financial officer, provost, president, and governing board. The participants of my study needed to work collaboratively with these and other players on campus, functioning like middle managers because they have limited authority, compared to leaders like presidents and provosts. The insight they share may be helpful to further understand the experience in creating urgency around meeting a dire campus need: recruiting new students. Enrollment management leaders must advocate for resources to achieve the enrollment goals established by their executive team and boards. Without sufficient resources, including technology appropriate to reach the modern prospective student, recruitment can suffer, reflecting poorly on the enrollment manager leader.

In addition, understanding how leaders manage change effectively, regardless of the specific phenomenon, is important for dynamic organizations (Kezar, 2014). Qualitative data that help us understand the experience of these enrollment management leaders around one specific initiative may help others navigate organizational politics and lead their own change efforts. The findings of this study can be critical to the learning of leaders in higher education by offering rich descriptions of participant experiences working within their own organizational politics, providing real life stories on what was successful or not.

\section{Conclusion}

In this chapter, I have established the importance of enrollment management in higher education, especially for small, private, primarily undergraduate colleges. Leaders in the enrollment management role face challenges such as changing demographics resulting in a declining traditional-aged population, decreased funding, and increased 
expectations for use of technology. These leaders often are on the executive team, but do not hold the same level of positional authority as presidents and therefore must utilize effective change management and political skills to advocate for resources such as the adoption of new technology. My research seeks to understand the phenomenon of leading this change effort in the early stages of adoption to inform other higher education leaders who may also be initiating change on a college campus.

In Chapter 2, I review literature pertinent to this study, as well as explain the frameworks in more detail. First, I will review literature on the enrollment management function, and the emerging leadership role associated with this area. I then review customer relationship management (CRM) in higher education, and finally review literature on change management and politics in higher education. Chapter 3 outlines the research methods used for this study. Specific detail around identifying and inviting participants, the interview protocol, and data analysis are also described to help readers understand my process. In Chapter 4, I present the findings from the data analyzed, and in Chapter 5, I answer the research question, as well as share the captured essence of participants' experiences. Chapter 5 also presents conclusions and implications for practice and further research. 


\section{CHAPTER 2: LITERATURE REVIEW}

My literature review has three main components. I start by reviewing literature related to the concept of enrollment management and the role of its leaders in higher education. I then review scholarship focused on customer relationship management (CRM) in higher education, both as a concept and a technology solution. Finally, I review literature regarding the conceptual frames that informed my study: Kotter's (2012) first two stages of change and politics in higher education, and also introduce Bolman and Gallos (2011) political frame as a contextual factor that influences change management.

\section{Enrollment Management and Leadership}

\section{History of Enrollment Management}

The concept of "enrollment management," which was followed by "strategic enrollment management," is broadly defined as a systematic set of activities to influence students on their college choice and continued enrollment (Hossler, 2015). The importance of managing enrollment for colleges and universities in the U.S. has become increasingly important because of several historical events, beginning with the GI Bill in the 1950s. The GI Bill increased overall participation in postsecondary education (Heller, 2006; Hossler, 2015) at both private and public institutions (Heller, 2006). Into the 1960s, the number of community colleges grew across the U.S. and enrollment increased across public institutions. From roughly the mid-1950s through the mid-1960s, enrollment at public institutions increased substantially while enrollment at private institutions grew only minimally (Heller, 2006). The substantial increase in public school enrollment during this time frame was partially attributed to shifting views of policymakers that led to increased financial support for public higher education. 
As the U.S. government compared its education system to that of other countries - many of which completely funded postsecondary education — pressure to improve the number of college graduates increased. Recognizing the public benefits of college graduates, including higher earning potential, increased community involvement, more new businesses and jobs, as well as lower unemployment and prison rates (Bowen, 1980), many state and local governments increased support for their public institutions (Hossler, 2015). State support for higher education grew steadily from about 1950 to 1980 (Heller, 2006) and translated to lower tuition rates at public colleges and universities (Hossler, 2015), resulting in a substantial increase in enrollment at public institutions. Increased enrollment at public institutions led to greater competition for students among all institutions. Private institutions, in particular, felt the impact as early as 1966 , and realized they needed to begin marketing and actively recruiting in order to maintain healthy enrollments (Hossler, 2015).

Significant growth in federal and state support and enrollment continued from 1950 to 1980 . However, from 1980 to 1996 , state support for higher education decreased by about $8 \%$ while federal support declined by about $3 \%$ - a trend that continued through 2006 (Heller, 2006). Reduced funding led to the "privatization" of higher education, a trend that continues, as these colleges and universities turned to private methods of revenue generation, including a focus on increasing enrollment as tuition revenue dependency increased (Hillman, 2011; Priest \& St. John, 2006; Schultz \& Lucido, 2011).

Changes in U.S. demographics are important factors in the work of enrollment management. In the mid-1970s, the number of high school graduates was predicted to decline by as much as $42 \%$, which also drove competition between all postsecondary 
institutions for a diminishing pool of traditional-aged prospective students (Hossler, 2015; Schultz \& Lucido, 2011). Private schools had already begun to focus on marketing and recruitment to maintain enrollment, and public institutions found themselves quickly following suit in light of forecasts of decreased funding and a declining market (Hossler, 2015).

The shifts in public policy and funding, creation of more postsecondary options, and changing demographics, all continued to increase the need to strategically manage enrollment. As emphasis was placed on student recruitment and retention, colleges and universities began to integrate functions related to enrollment into their organizational structures (Hossler, 2015; Schultz \& Lucido, 2011). The process of recruitment and retention continued to develop into an organizational concept and the term enrollment management emerged in the 1970s. The term is often credited to Jack Maguire who used it to describe his efforts at Boston College to recruit and retain students (Hossler, 2015). Institutions recognized the importance of enrollment management as a way to develop teams to focus on a comprehensive plan to achieve and maintain enrollment goals.

In the 1980s, The College Board and Loyola University of Chicago offered the first conference focused on managing enrollments (Hossler, 2015; Hossler \& Kalsbeek, 2008). At that time, the key functions of enrollment management were: marketing for student recruitment, developing and executing retention efforts, and using financial aid strategies to meet enrollment goals. By 1991, the American Association of Collegiate Registrars and Admissions Officers (AACRAO) held its first annual Strategic Enrollment Management (SEM) conference and although it may have been sparsely attended at first, 
by 2012 this conference drew 727 registrants from 300 institutions across nine countries (Hossler, 2015; Hossler \& Kalsbeek, 2008).

As enrollment management became recognized as a key component on campuses, it was important to determine how to fit this team in with existing campus structures, the degree of centralization needed, and how to define the role and responsibilities of those leading these teams. By 2004, most colleges reported having a formal position responsible for enrollment management, many of whom were at the vice president level (Schultz \& Lucido, 2011). The degree of centralization of enrollment management functions across campus still varies and has been the focus of studies using organizational theory, but nearly all colleges now have a formal structure to focus on managing enrollment (Hossler, Kalsbeek, \& Bontrager, 2015; Schultz \& Lucido, 2011).

There is a lack of empirical evidence that demonstrates any particular enrollment management structure is more effective than another, however, some studies have helped to inform the profession (Hossler et al., 2015). Ultimately, the structure is likely to reflect the skill of the leader, the situation, and the culture of the institution (Hossler et al., 2015), yet most literature offers a general consensus about the importance of enrollment management and key factors for success (Hope, 2017; Hossler \& Kalsbeek, 2008; Langston, Wyant, \& Scheid, 2016; Schultz \& Lucido, 2011; Sutton, 2016). One such factor is that the leader of enrollment management should be a part of the college's senior management team, and regardless of the title and reporting line, the president, chief academic officer, chief financial officer, and board members must understand and appreciate this role and function (Hope, 2017; Hossler et al., 2015; Hossler \& Kalsbeek, 2008; Langston et al., 2016; Sutton, 2016; Wymbs, 2016). Although titles of the 
enrollment management leaders are often "vice president," these leaders often function like middle managers who are responsible for recruitment and retention, yet must rely on approval from the president, and other cabinet members to make major decisions.

Other important factors to successful enrollment management include having a clear enrollment management plan, using research and data to inform planning and decisions, emphasizing serving students, having access to up-to-date information systems and technology, and including strategies to meet enrollment goals in the institution's overall marketing plan (Hope, 2017; Hossler \& Kalsbeek, 2008; Langston et al., 2016; Schultz \& Lucido, 2011; Sutton, 2016; Wymbs, 2016).

Strategic enrollment management has become widely recognized as an important function on college campuses, which is evident through the high-level administrators who oversee these functions, national conferences, scholarly publications, and related graduate courses and tracks of study within higher education programs (Hossler, 2015). My study focuses on the experiences of those in leadership roles within the enrollment management function, thus I next will review literature more specific to this role.

\section{Enrollment Management Leaders and Their Stakeholders}

As the function of strategic enrollment management was developing on college campuses, leadership roles for this area began to emerge; since then, these positions have already seen significant changes. In the late 1980s, the president or faculty senate would have instructed the enrollment management leaders to recruit more, higher-profile students with little to no additional resources (Dennis, 2014). By 2014, the enrollment management leader had become a critical player on campus, often on the president's cabinet, who must work with different constituents to involve everyone in a 
comprehensive enrollment plan (Dennis, 2014; Sutton, 2016). What started as a role developed out of necessity has grown into a key position on college campuses requiring skills such as building relationships and promoting teamwork, staying abreast of current trends in the market and within education, analyzing past enrollment data to forecast future enrollments, and integrating the use of technology in enrollment management (Lingrell, 2014; Stewart, 2004). The enrollment management leader must be a "visionary, facilitator, and collaborator" (Stewart, 2004, p. 21) to successfully keep enrollment goals at the forefront of institutional planning.

Although the role of the enrollment management leader may vary based on institution type and size, having the ability to form and manage relationships is always a critical skill (Dennis, 2012, 2014; Henderson, 2012; Hope, 2017; Wymbs, 2016). Relationships with colleagues are important because the leader is expected to involve all stakeholders in enrollment management, advocate for resources, and promote teamwork (Stewart, 2004). Enrollment management leaders should develop relationships with academic leaders and faculty so as to create programs of study that meet student demands, and establish a joint plan to sell programs to prospective students (Hope, 2017). Joint planning and creating an inclusive plan promotes buy-in from academics and increases shared responsibility for enrollment (Hope, 2017).

Student affairs is another area important to enrollment management, especially for effectively serving recruited students so they may be successful and thus retained (Dennis, 2012; Henderson, 2012; Hope, 2017; Sutton, 2016). An effective strategic enrollment plan will entail finding students who are a good fit for the institution, which includes ensuring the campus is equipped to help each student succeed both academically 
and financially, as well as outside the classroom (Henderson, 2012; Sutton, 2016). A strong relationship with the chief financial officer (CFO) is also important. The CFO is involved with institutional aid discounting, often used to manage enrollment; relies on enrollment to project overall net tuition revenue; and plays a role in allocating resources that impact enrollment (Hossler et al., 2014).

A relationship with the senior administrative team is so critical that many colleges include the chief enrollment officer on that team, which can help address conflicting enrollment goals from top administration (Hossler \& Kalsbeek, 2008). It is the responsibility of the enrollment management leader to help the campus leadership team, and often the governing board, understand the implications of enrollment management decisions (Hossler \& Kalsbeek, 2008). Ultimately, positive relationships with nearly every campus entity are important for enrollment management leaders. These leaders are responsible for ensuring actions to stabilize enrollment, while presenting enrollment management as a campus-wide issue (Stewart, 2004); yet, they are often the first one blamed when enrollment goals are not met (Dennis, 2014).

Enrollment leaders must also be adept at finding and analyzing data, and leading action based on their findings (Dennis, 2014; Hope, 2017; Langston et al., 2016; Stewart, 2004; Wymbs, 2016). As the enrollment management function has developed, use of data has become increasingly important and includes collecting information on the demographics of current and past students against success rate, past recruitment funnel metrics, retention rates, placement rates of graduates, financial aid rates, and impact on enrollment (Wymbs, 2016). The most important use of these data is to help the enrollment manager accurately predict enrollment for the institution, which often drives 
the campus budget (Langston et al., 2016). Data are also used in marketing, as more outreach and engagement is electronic and tracked to help recruiters determine how best to engage with potential best-fit students based on past trends. It is important for leaders to not only collect internal data on past enrollment trends, but also to research external trends in higher education and the student market to develop a plan of action (Dennis, 2012; Langston \& Scheid, 2014). In fact, many enrollment management leaders would be better served spending more time researching external trends and exploring those in comparison to internal data, rather than getting caught up in day-to-day activities (Dennis, 2012; Lingrell, 2014).

The ability to use and research technology is another essential skill for enrollment management leaders. Enrollment management has become increasingly dependent on technology for managing student information internally, analyzing data for enrollment forecasting, and also for serving students during recruitment and retention phases (Dennis, 2012; Stewart, 2004; Langston \& Scheid, 2014). Technology use spans internal information systems, data management systems, customer relationship management systems, and web-based services. A good working relationship with the campus information technology team is also necessary for enrollment management success (Hossler \& Kalsbeek, 2008).

Enrollment management crosses several campus functions, and thus the role of the enrollment management leader can be daunting. As with many other leadership positions, key skills include goal setting; forming coalitions; and being a good communicator, politically savvy, and flexible (Dennis, 2012). The list of skills now includes the need to be a visionary with a focus on the future, the ability to research, use 
data, and weave together the analysis of data and trends with technology to maintain a progressive enrollment management plan (Dennis, 2012).

\section{CRM Adoption, Technology, and Student Recruitment}

\section{CRM in Higher Education}

The concept of customer relationship management (CRM) first became popular in business as the focus on obtaining and retaining customers shifted from a transactional model to a relationship-based version (Siu, 2016). Early models for a complete CRM strategy encompassed four stages: exploration, expansion, commitment, and continuation or dissolution (Bejou, 2005). Several studies have affirmed this coordinated focus on customers as critical for businesses to sustain themselves (Siu, 2016).

As more businesses adopted CRM strategies and competition for students on colleges campuses increased, the concept of student as a consumer and customer emerged (Bejou, 2005; Guilbault, 2016; Lewison \& Hawes, 2007; Rigo et al., 2016; Schultz \& Lucido, 2011). Many institutions now operate more like businesses serving customers (Schultz \& Lucido, 2011), even though many in higher education reject the view of the student as the customer (Guilbault, 2016; Oluseye, Tairat, \& Emmanuel, 2014). Some in higher education make a case that viewing students as customers threatens academic integrity; yet, the trend continues, and cases are made to strike a balance between serving students and maintaining academic standards (Guilbault, 2016).

For higher education institutions, the CRM process translates to different stages: recruitment, enrollment management, retention and progression, and post-graduate (Bejou, 2005). Marketing and admissions functions are especially involved in the early stage of CRM - recruitment (Klie, 2013; Langston \& Loreto, 2017). Applying concepts 
around relationship management and marketing to higher education recruitment entails attracting prospective students through building brand loyalty and developing positive relationships (Langston \& Loreto, 2017). A strong CRM strategy helps schools identify the right prospective students and personally engage with them through multiple stages of the recruitment process. Targeted marketing entails understanding the specific market being served and directing messages accordingly, rather than using mass marketing methods designed to reach everyone and anyone (Lewison \& Hawes, 2007).

The adoption of CRM processes quickly and nearly simultaneously led to the creation of information technology systems to facilitate CRM (Seeman \& O'Hara, 2006). Thus, CRM is referred to as both a business strategy and a technology-software set (Seeman \& O'Hara, 2006). Technology is used to facilitate and automate the CRM process across several functions in a college or university, from admissions and course registration to annual financial aid packaging. Although the fundamentals of college recruiting remain centered on connecting and building relationships, the traditional means of doing so are no longer the only, or most effective, methods available (Lindbeck \& Fodrey, 2009). According to a recent report, $64 \%$ of campuses report using at least one CRM technology system (Langston et al., 2017).

The technological component of CRM has helped schools better track their process and increase the level of personalization in reaching prospective students, but also brings challenges (Langston \& Scheid, 2017; Pember, Owens, \& Yaghi, 2014). Many colleges and universities are integrating technology into their recruitment process in response to the changing demographics, but there is still opportunity to improve outreach and associated return on investment (Lindbeck \& Fodrey, 2010). 
Of schools using CRM technology, $75 \%$ report they do not believe they are maximizing the capacity of the technology (Klie, 2013). Many schools reported their primary goal in obtaining CRM technology was to boost enrollment and automate communication, followed by tracking marketing results and reducing costs of recruitment (Klie, 2013). Thus, the use of CRM technology is often focused more on student outreach and less on the complete work flow process the technology could help streamline. Full use of CRM technology can help with other aspects of recruitment and continue to focus on serving students throughout their life cycle (Klie, 2013).

Challenges in using technology often begin with adoption, and continue to be problematic when teams are not fully supportive or fail to understand the technology. Cases around failure in adopting CRM technology indicate that success must rely on more than just the technical component- the adoption represents a significant change in the business operation and thus requires adequate change management (Siu, 2016). Also, teams cannot become overly reliant on the technology component to do everything for them. The technology helps teams manage the information, process, and automates communication, but does not replace the human element of CRM (Siu, 2016).

Most studies focus on the technical component of adoption and thus literature on the human interaction with the technology is limited (Siu, 2016), yet previous studies indicate support from top-level management is a key determining factor of success ( $\mathrm{Al}$ Mumun \& Islam, 2013; Klie, 2013; Langston \& Scheid, 2017; Pember et al., 2014; Rigo et al., 2016). If adoption of the CRM technology is not an institution-wide decision, the staff's use of the system may be limited, thus less effective. Staff may also be slow to adopt and learn the new technology if they are not involved in the selection and 
implementation process or if they sense top management is not supportive of the change (Langston \& Scheid, 2017; Pember et al., 2014).

\section{Student Expectations and Technology}

For prospective, traditional-aged undergraduate students, technology is a way of life (Levine \& Dean, 2013). Approximately 95\% of U.S. adults aged 18-24 have a cellphone and only $1 \%$ do not have any type of computer, phone, or tablet. (Levine $\&$ Dean, 2013). Nearly three quarters of teenagers aged 13-17 either have a smartphone or have access to a smartphone, which gives them access to the internet, apps, and texting (Lenhart, 2005). A 2015 Pew report indicated 24\% of teens indicated they were online almost constantly and 94\% were on daily (Lenhart, 2015). Students looking at colleges expect technology to be a part of their educational experience both for instruction and learning as well as processes within the college (Seeman \& O’Hara, 2006). Computers, mobile phones, messaging, texting, and the internet were a part of their world growing up, and by the time they were in middle school they had Google, Skype, YouTube, Twitter, and Facebook (Levine \& Dean, 2013).

Another survey of several hundred first-year college students indicated technology was important to them during the college shopping process (Lindbeck \& Fodrey, 2010). Researchers found students emphasized the use of multimedia, simple web pages, personalized messages, and relevant and practical contact. Students did not take interest in information that was not directly related to what matters to them (Lindbeck \& Fodrey, 2010). Their findings reinforce that this generation expects technology to be a part of their daily communication and learning, and colleges must plan 
to reach them in their space when developing marketing and recruitment plans (Levine \& Dean, 2013).

\section{Summary of Enrollment Management, CRM, and Technology}

The literature I have reviewed thus far has demonstrated the many changes our society and economy has seen over the last 30-40 years, warranting enrollment management becoming a key component of higher education institutions. Emphasis on managing enrollment led to the role of the chief enrollment officer on campuses, and the bringing together of several key areas such as recruitment, student services, financial aid, and marketing to develop a comprehensive enrollment plan. Leaders in this role are expected to stay abreast of national market trends and manage change as needed, maintain relationships with varying constituents, collect and use data to inform enrollment management planning, and understand how to best use technology to reach their target market and manage the recruitment process. Most of the research conducted regarding the adoption of technology to support enrollment management is tied in with campus-wide technology adoption and tends to be focused on numerical measurements and technical implications. However, very little research has been done around the human interaction related to enrollment management technology, or the leadership function of facilitating the change related to selecting CRM technology specifically to serve the recruitment of traditional-aged, prospective college students, prompting the interest in my study.

\section{Frames Guiding the Study}

My study focuses on the experience leaders had in leading change through the selection process of adopting technology for the primary purpose of recruiting students. 
To guide my study, I focused on the first two stages of Kotter's (2012) model for leading change. Before providing more detail about Kotter's model, I will first review additional literature around change management as it relates to higher education, and more specifically enrollment management. I will hone in on early stages of change around “mobilizing" or getting the change initiative started (Kezar, 2014, p.171). Next, I will introduce two specific themes from change models that will further direct my research: the need to create urgency and develop relationships resulting in coalitions. Coalition and relationship building is political (Kezar, 2014), thus I also introduce the political frame to provide context for my study.

\section{Change}

Flat or declining enrollment is often the result of a lack of planning and adaptation to external or environment changes (Kezar, 2014) forcing the need for change on a college campus. The emergence of strategic enrollment management has become a common function on campuses as many are finding themselves in an evolving and more competitive environment (Hossler, 2015; Schultz \& Lucindo, 2011). Leaders are seeking new ways to recruit and retain students, but are also exploring alternate revenue streams and ways to expand online programs (Hillman, 2011; Schultz \& Lucindo, 2011). The notion of students as consumers (Guilbault, 2016) and the related pressure for corporatization represents shifting values and foundations of higher education institutions that are more in line with corporate approaches (Hillman, 2011).

However, higher education institutions have deep roots in their traditions and are known for using traditional planning and approaches, and sometimes for being resistant to change (Bontrager \& Green, 2015; Hossler, 2015; Kezar, 2014). The push for rapid 
changes, including new initiatives such as technology adoption to increase enrollment, is incongruent with these traditional models of higher education (Manning, 2013).

Enrollment management leaders often finds themselves at the center of this incongruence, asked to increase enrollment, yet respect the traditions of their institution. To successfully meet goals, these leaders must have an understanding of the change process, which may entail adopting a new view of change (Kezar, 2014).

Change is not new to higher education, yet opinions differ as to how much institutions have really changed. Robert Zemsky argued that higher education is fundamentally operating the same now as in the 1980 s, because it is unable to effectively facilitate needed change (as cited in Bontrager \& Green, 2015). Although, others argue that change has occurred. For example, some critics indicated recent changes are "unprecedented," and Kezar (2014) outlined significant changes occurring throughout the history of higher education. As described in Chapter 1, many of these changes were driven by external forces, such as war and policy decisions that influenced funding access, and financial aid, rather than being intentionally driven from internal sources (Heller, 2006; Hossler, 2015; Kezar, 2014).

Through the last few decades, higher education has become more complex with more and more challenges, thus making the change process more important and daunting (Bontrager \& Green, 2015). The current environmental shifts calling for change in higher education are coming from multiple directions and pose a threat to leaders due to this complexity and a potential lack of resources (Kezar, 2014). Increased complexity is further compounded by the "tradition, inertia, and a potent political structure" (Bontrager \& Green, 2015, p. 532) that abound in institutions that have been around for centuries. To 
effectively lead higher education through change will require adopting new views of change itself (Kezar, 2014).

The rate of change in higher education continues to increase, and history has not necessarily prepared leaders to effectively manage new challenges (Kezar, 2014). Although leaders have learned from the past, new challenges are often growing at a faster rate than the skills of leaders (Kotter, 2012) and a common error made in leading change is to focus on the new initiative itself and not the change process needed to make it happen (Kezar, 2014). It is common for organizations that experience rapid growth to shift their attention to management in order to keep up with increased demands for production. Although this focus allows the organization to meet current demands, it shifts away from forward-thinking leadership and being ready to adapt to change. Successful transformation entails about 70\%-90\% leadership and 10\%-30\% management, yet the focus on management often continues to prevail (Kotter, 2012).

Leaders looking for ways to manage change have a plethora of models to choose from, some identified in the Harvard Business Review (2011) 10 Must Reads on Change Management. Based on years of experience, authors share stages, steps, processes, and phases for change management along with real-world examples on how each have worked for leaders. These models can help guide change leadership, yet is important for leaders to recognize that every situation will call for an adaptation of nearly any selected process (Kezar, 2014; Meyerson, 2011). Many of the models shared are considered too simplistic and leaders must recognize the need for not only adaptation of models, but multiple approaches to lead complex change (Kezar, 2014). As previously mentioned, the challenges facing enrollment management are embedded in higher education institutions 
bound by hard traditional approaches, making the change process complex. Leaders charged with increasing enrollment with change initiatives must understand these complexities and engage change on their campuses (Kezar, 2014) using key components of the many change models available.

Kotter's eight stages of leading change. One model leaders use is Kotter's (2012) eight stages of leading change. Each of the eight stages is intended to help the leader avoid common mistakes made during the change process: allowing too much complacency; failing to gain powerful support through a guiding coalition; underestimating vision; under communicating the vision; permitting obstacles; neglecting to create short term wins; declaring victory prematurely; and failure to anchor the change in the culture (Kotter, 2012). Kotter identified eight stages to overcome these mistakes: 1) establishing a sense of urgency; 2) forming a powerful guiding coalition; 3) creating a vision; 4) communicating the vision; 5) empowering others to act on the vision; 6) planning for and creating short-term wins, 7) consolidating improvements and producing still more changes; and 8) institutionalizing new approaches.

For the purposes of my study, I focus on the first two of these stages to help me frame and understand the experience of leaders in the early stages of initiating change. These early stages are part of the mobilization phase, often described in political models (Kezar, 2014). Kotter's (2012) remaining six stages are also relevant in studying change initiatives; however, a focus on the first two stages allowed further depth in understanding the experience of the leader within the early stages of their change initiative, which is the focus of my research. These first two stages are key factors in eliciting change when many resist it, as in higher education (Kezar, 2014). Additionally, 
the concepts of creating urgency and forming coalitions are supported in other models of change management, as indicated next.

Establishing urgency. It is common for people within organizations to be complacent about adopting change, not recognizing crisis or believing it is not a real threat to them, thus ignoring new initiatives or waiting for the change to pass (Garvin \& Roberto, 2011). Within higher education the same is true, and leaders have not responded proactively to apparent shifts in the environment that call for change on campus, hoping for the situation to simply get better (Kezar, 2014). Often employees within an organization recognize signs of trouble and admit it; however, they often cite that the troubles are general to the industry or elsewhere within the organization. Teams point to other teams internally, managers point to their staff, and staff point to their managers. Yet, no one really has a sense that the problem is large enough or bad enough to really have consequences, or that it is their responsibility to do anything (Kotter, 2012).

Urgency is created by removing sources of complacency (Kotter, 2012). Many managers take some actions to remove complacency, such as eliminating signs of excess, setting higher standards, changing the focus of measurement standards, or increasing external feedback. However, most of these actions are not bold enough or sustained long enough to create a real sense of urgency (Kotter, 2012), often the hardest part of paving the way for change to occur (Kim \& Mauborgne, 2011). Steps and stages in other models include this early creation of urgency as well, indicating the importance of getting attention and convincing the team change is imperative (Beer, Eisenstat, \& Spector 2011; Garvin \& Roberto, 2011; Kim \& Mauborgne, 2011). Creating a visible crisis is helpful in getting attention and elevating urgency, as illustrated by one example of a hospital CEO 
who notified employees of their dire financial situation, leading to a potential sale (Garvin \& Roberto, 2011). Another example is the Associate Provost for the Boston University College of Medicine, who established urgency by pointing out the loss of qualified students to their programs as a result of curriculum (Dasgupta, Symes, \& Hyman, 2015). Likewise, leaders in enrollment management establish urgency by pointing out the decline in enrollment leading to decreased net tuition revenue for the college, as well as implications for the college (Hossler et al., 2014). As more colleges face closure or mergers (Dennis, 2014), the situation becomes real for employees and can aid the enrollment management leader in establishing this urgency.

It is important for leaders to remember the importance of creating urgency early on to set the stage for change (Beer et al., 2011; Garvin \& Roberto, 2011; Kim \& Mauborgne, 2011; Kotter, 2012). Any change effort is difficult to lead through the next stages unless most of the management team believes the status quo is unacceptable. Later stages of change are not likely to be successful unless $75 \%$ of the team (Kotter, 2012), and nearly all of the top leaders, believe it is essential and are committed to the initiative (Beer et al., 2011; Kotter, 2012). Managers often move to the next stage or two of a change initiative and see some movement, making it tempting to skip this stage. However, the complacency usually catches up, slowing down momentum for the change (Kotter, 2012).

Creating a guiding coalition. After a sense of urgency is established, the next step for leaders to get change initiated is building relationships with key individuals to form a coalition or alliance to champion the change (Kim \& Mauborgne, 2011; Kotter, 2012; Meyerson, 2011). When the change is major, it requires a powerful group to 
sustain the change effort from initiation through the final phases. One common mistake at this stage of change is for someone to try to do it themselves (Kotter, 2012). Going it alone usually entails one person, perhaps the enrollment management leader or university president, leading a change effort and making all decisions by themselves. One person can make some progress on their own using tactics such as those offered by Meyerson (2011), considered radically quiet. These entail actions and behaviors that quietly disrupt and establish value and identity, consistently call out the opposition, and capitalize on newly presented opportunities (Meyerson, 2011). One person may make a difference with these techniques, however, forming alliances expands their reach to others, access to resources, and likelihood the change will take hold (Meyerson, 2011). Putting time into identifying people who can be the key influencers and motivating them is sometimes better than going it alone or spending time drafting detailed incentive plans to get everyone on board (Kim \& Mauborgne, 2011). Identifying the guiding coalition to have a team to influence the change is also important in a world where the speed of market and technological change, such as adopting a CRM, must be taken into account, and one single person going it alone may move things too slowly, or not at all (Kotter, 2012).

The successful guiding coalition must have the right membership (Kim \& Mauborgne, 2011; Kotter, 2012). Kotter identified four key characteristics essential to these groups. The first is to have enough position power among the players to prevent others from blocking progress. The second characteristic is expertise; the group must represent a wide range of relevant knowledge and points of view. Third is credibility, as the coalition must be reputable within the organization to be taken seriously. Last, is leadership, which is particularly important. Having a balance of both management and 
leadership skills helps to keep the process itself on track (i.e., management), while driving the actual change (i.e., leadership).

An example of identifying coalition members is to include respected insiders on the senior team or coalition (Kim \& Mauborgne, 2011). These people represent both positional power and credibility among the employees of an organization. They can help read the climate of a wider group to identify potential opposition, thus allowing for intervention, such as sharing relevant facts and information, to address concerns early on (Kim \& Mauborgne, 2011). Anticipating the naysayers sometimes means enlisting their support and membership on the coalition to build the power position (Kim \& Mauborgne, 2011). For example, in the adoption of CRM technology for higher education student recruitment, the enrollment management leader could engage the campus technology leader to represent positional power, expertise, and credibility on the coalition.

Three key steps to building a successful guiding coalition are: 1) find the right people, with strong position power, credibility, expertise and a good balance of leadership and management skills; 2) create trust through planned events and joint activities to build the team; and 3) develop a common goal that is logical yet appealing enough to inspire the team (Kotter, 2012). To successfully create urgency and build a coalition, leaders may benefit from understanding higher education as a political arena. Next, I introduce the political frame; understanding and applying this frame provided additional insight into the change process I explored in my study.

\section{Political Frame}

Successful leaders in higher education seek to learn who the influencers are within their organization and align themselves accordingly. This is a political process. 
Politics exist within higher education and must be recognized as a force that can help or hinder change (Bolman \& Gallos, 2011). Political perspectives may describe higher education institutions better than other models, according to organizational theorists who study higher education (Manning, 2013). Institutions of higher education are organizations with the same challenges for leaders as most any organization, non-profit and corporate alike. At a time when colleges and universities are competing for fewer students with greater expectations, this same understanding of the political terrain of their institution is important for leaders. Leaders who are able to understand and exercise political skills will have a greater impact on changing their organization (Bolman \& Deal, 2008).

Bolman and Gallos (2011) and Manning (2013) both apply the political frame to higher education and use the metaphor of a jungle to emphasize that campuses are very political environments. This view may overemphasize the negative aspect of politics, but it is important for leaders to also embrace the positive aspects of this frame. The negative side brings attention to rivalry, backstabbing, and competition but the positive can balance this out with a focus on relationship building and clarifying goals (Manning, 2013). Leaders in higher education often lack understanding of the role politics plays, as well as political skills, which can result in costly mistakes. In order to be successful, campus leaders must identify the politics on their campus and learn to leverage political realities.

Bolman and Deal's (2008) political frame provides a lens to help leaders recognize sources of power, conflict, and decision making in organizations, including institutions of higher education. Key sources of power include position power, control of 
rewards, coercive power, expertise, personal power, alliances and networks, and access and control of agendas (Bolman \& Deal, 2008, French \& Raven, 2005). Upper level positions, such as the president, dean, or provost, are perceived as having power. However, there is a distinct difference between power and authority (Bush, 2003; Pfeffer, 2005). Leaders in higher education often have the authority to make a decision regarding change because of their title or position within the college, but may not have the political power needed to implement and sustain the change (Manning, 2013).

Authority is defined as the legitimate power bestowed upon individuals usually due to their position within a formal structure (Bolman \& Deal, 2008; Bush, 2003; Pfeffer, 2005), such as the president or dean, but the other individuals and groups on a college campus who are usually the recipients of these decisions may influence the decision-maker using other forms of power (Bolman \& Deal, 2008; Pfeffer, 2005). Influence is the ability to affect others based on personal power gained by means such as relationships and expertise (Bush, 2003). French and Raven (2005) defined this process as a person, $P$, influenced by another person, role, group or subgroup as a social agent, or $O$. The relationship of power, influence, and change exists in that power equals influence, and influence equals change. Social power is the potential ability of $O$ to influence $P$ to change behaviors, opinions, attitudes, goals, or needs, regardless of position and authority. Leaders championing change on a college campus, such as a vice president or director of enrollment management, are in the role of $O$, who have the potential to influence $P$, who may be the president, the CFO, their own team, and/or others. These same leaders also may be in a position of authority, yet need to be aware of the social agents with whom they work to truly understand the influence each has within 
the organization. Leaders relying solely on positional power (authority) can experience resistance and be over-ruled by others with different sources of power. A leader in a position of authority must fill the gap between their positional power and what is needed to be successful, which means learning to use other sources of power to accomplish their goals and lead change (Bolman \& Deal, 2008).

A key component of creating a guiding coalition is developing relationships with people who hold both positional and influential power (Bolman \& Deal, 2008; Kim \& Mauborgne, 2011; Kotter, 2012; Manning, 2013). To help identify the right people for the coalition, leaders can map the political terrain of their campus (Bolman \& Deal, 2008; Bolman \& Gallos, 2011). This process helps leaders understand the players within an organization. To create this map, leaders need to discover channels of informal communication, identify those with influence, analyze their options for getting action from key players, and also anticipate alternative strategies. Leaders should ask themselves who they need to help them and then take steps to build relationships with those people, perhaps rallying them to be on the guiding coalition to help build a base of power.

Conflict and power. The political frame helps leaders understand and use conflict to forward their change initiative. Change is associated with conflict and leaders who are prepared to manage such conflict as part of change will reap the benefits of change (Rahim, 2011). Opposing views on conflict exist, leading to the acknowledgement that conflict has both functional and dysfunctional outcomes (Rahim, 2011). By understanding potential negative effects, leaders can minimize the negative and focus on directing themselves and their coalition on the functional, positive effects 
(Bolman \& Deal, 2008; Rahim, 2011). Potential negative effects of conflict include increased job stress and burnout of employees, reduced communication, distrust, and increased resistance to change (Rahim, 2011). On the positive side, conflict challenges current day-to-day routines and assumptions, and drives social change and innovation (Bolman \& Deal, 2008), often leading to increased productivity, synergistic solutions, and alternative solutions (Rahim, 2011).

Organizations are coalitions with ongoing contests between individual and group interests that often arise when it comes to the allocation of scarce resources (Bolman \& Gallos, 2011; Manning, 2013), such as the financial commitment to a new enrollment management system. College campuses are comprised of broad groups, including administrators, faculty, staff, students, alumni, and alumnae, as well as external stakeholders (Bolman \& Gallos, 2011; Manning, 2013). Groups within the institution may further divide, depending on the size and structure of the school. All players within every group have their own view of the institution's mission and priorities that lead them to believe how resources should be allocated, but those views are not always expressed transparently. Differences in beliefs often surface when change is apparent, creating conflict and making power itself a key resource (Bolman \& Gallos, 2011). The politically savvy leader is skilled in bargaining and negotiating to manage conflict. Effective bargaining includes the ability to separate people from problems, a focus on interests and not positions, investing in options for mutual gain, and insisting on the use of objective criteria (Bolman \& Deal, 2008).

Leaders skilled at engaging the political frame demonstrate that conflict is something normal and expected in a change initiative and can result in positive, 
functional, outcomes (Rahim, 2011). As leaders in enrollment management recognize the need for new practices and technology, they should also recognize the various views different stakeholders have in adopting change, which will result in conflict. Poorly managed conflict can lead to power struggles and poor decisions that can be devastating (Bolman \& Deal, 2008).

\section{Conclusion}

In this chapter, I presented a review of literature that informed and guided my research. The review began with the emergence of enrollment management as a key function in higher education, the role of relationships in strategic enrollment management, followed by the process of adopting technology for CRM to create efficiencies and align with the expectations of prospective students. Finally, I reviewed literature related to early stages of managing change and how politics on a college campus can shape change initiatives. Chapter 3 outlines the research methods used for this study. Specific detail about the methodology and design, including the processes for identifying and inviting participants, data collection, and analysis are also described. In Chapter 4, I present the emergent themes from the data analyzed, and in Chapter 5, I answer the research question within the context of the study's framework and related literature. Chapter 5 also presents conclusions and implications for practice and further research. 


\section{CHAPTER 3: METHODOLOGY AND RESEARCH DESIGN}

As the enrollment game becomes more competitive for colleges, many are turning to vendors to implement marketing and Customer Relationship Management (CRM) solutions, such as the Enrollment Marketing Platform (EMP), to help them reach, engage, and ultimately recruit their target market. The purpose of this study was to understand the phenomenon of leading change through the selections and adoption of the EMP from the perspective of enrollment management leaders. I framed the study using Kotter's (2012) first two stages of change, incorporating Bolman and Deal's (2008) political frame with the second stage of change management. The research question guiding this study was: How do enrollment management leaders at small, private, primarily undergraduate colleges describe their experience establishing urgency and creating coalitions as they led the selection process of adopting the EMP technology for the primary purpose of recruiting students?

\section{Research Design}

Case studies are bounded by time and activity and allow the researcher to provide an in-depth review of a program, event, or individual (Creswell, 2009). Case studies also work well when exploring questions of "how" or "why" and when the research does not have control over the participants actions or behavior (Yin, 2014). This was appropriate for my study as I focused on leaders who had all experienced the same phenomenon: leading change to select and then adopt the EMP for student recruitment. In addition to having the same experience, the participants were also all at similar institution types and had led the change process between January of 2015 and July of 2017, further defining the case. 


\section{Participants}

The company for which I work was made aware of the study and volunteered to support the research before the proposal was submitted. Once the research proposal was approved by my advisor and dissertation committee, I obtained approval from the University of Missouri Institutional Research Board (IRB) to ensure my research used appropriate methods to protect participants.

After approval by the IRB, I obtained a list of the individuals who met my criteria from Liaison International. Liaison International acquired the company that developed the EMP in November of 2014. Due to the ownership change and the need to capture a collective essence, I chose to restrict participation in two ways. First, all participants purchased the EMP when the company was under new ownership, between January 2015 and June 2017. The reason for the specific timeframe was to assure the process occurred under the new ownership, and that limited time had passed so their experiences would be easier to recall. Second, participants were enrollment management leaders at institutions focused on undergraduate education, enrolling fewer than 5,000 students. I chose to focus on small schools because they are often more dependent on funding from enrollment and see the result of improved fiscal health with increased enrollment (Dalton \& Somers, 2015). A total of 16 people met these criteria, and nearly half of them were either no longer at the same school, or no longer in the same position held at the time of the EMP selection.

\section{Recruitment}

My goal was to have all 16 leaders agree to participate. I sent email invitations to all 16, asking them to consider participating in my study (see Appendix A for recruitment 
email). The invitation described the purpose of the study and expected time commitment for participation. The invitation also assured potential participants of confidentiality and detailed how they could contact me if they were willing to participate. It was my intention to conduct the interviews in September, which is often a busy time for admissions, so recruitment took longer than I would have preferred.

Less than half of the people responded quickly, and others responded after I sent two additional reminder emails. Three people agreed to participate and then became unresponsive for several weeks, but eventually scheduled an interview. Two people declined to participate; one stated they did not have the time and the other was working at a college that was closed due to wildfires in their area. Two people, who were no longer in their role, declined to participate and referred me to colleagues. One of these referrals also declined to be interviewed due to time constraints, and I was unable to get a response from the other person referred to me, who, I learned, was also no longer at the school. In the end, 12 participants agreed to an interview and I conducted interviews with each of them. Once participants agreed, I sent a confirmation email, welcoming them to the study and thanking them in advance for their time (see Appendix B for confirmation email.) That email also included potential dates, times, and modes for the interview; and the informed consent document (see Appendix C).

\section{Data Collection}

Studies that focus on individual experiences often rely on interview strategies (Merriam, 2016). The interview is a common form of data collection in case study research (Yin, 2014). Smith et al. (2009) described in-depth interviews as conversations with purpose: to facilitate interactions that allow participants to tell their own stories in 
their own words. During the interview process, the goal is for the participant to do most of the talking, as the researcher listens and captures the story. Yin (2014) also describes interviews being more fluid and conversational, following a general line of inquiry and carefully posing questions to allow the participants to open up rather than be defensive. My interview questions were designed to initiate conversation during the interview, inviting the participant to fully divulge the experience in their own words. I developed an initial set of questions to ask each participant then used additional semi-structured, openended questions, and probing statements to encourage more detailed responses. Questions served more as a guide and checklist rather than a rigid list to be followed. Although the primary goal was to initiate dialogue to learn how participants described their experience, the list of questions functioned as a dependability tool to keep me focused during the interviews (see Appendix D for interview protocol).

Although some studies are designed for individuals to participate in multiple interviews (Seidman, 2006), my study was based on a single interview with each participant. Participants were all busy working professionals. I was concerned that they may have been deterred from being a part of my study had I requested multiple interviews. Due to participants being located in a variety of different locations in the United States, and lack of resources to travel to interview participants in person, I relied on GoToMeeting to conduct the interviews. This allowed me to more easily and less expensively collect data and still allowed opportunities to observe facial expressions that may help me make more meaning of the data. Each interview lasted from $60-90$ minutes and the audio was recorded. Although we were able to see each other during the interviews, video was not recorded to protect the privacy of the participants. 
At the start of each interview, I reviewed the purpose of the study and consent information. I also ensured the participant of confidentiality and offered to answer any additional questions. Each participant was asked to select a pseudonym for future use in the transcripts and findings. I then asked for permission to record the audio portion of our interview. All participants agreed to be recorded. Recordings were initially secured within a private, password protected, GoToMeeting account, then immediately moved to a secure drive before being transcribed. The transcriptions were stored on a secure drive. Once the interviews were transcribed by a professional transcription service, I destroyed the recorded audio files. I will keep the transcribed interviews for 7 years, as required by the University of Missouri Institutional Review Board.

Additionally, I kept a journal throughout the data collection process. This allowed me to document ongoing observations and reflect upon the interview processes and adjust as needed. This documentation served as a tool to check my own assumptions as a researcher who had experienced the same phenomenon. It also helped me begin to identify potential themes as they emerged, and served as an additional mechanism to reflect upon my own intake and interpretation of what participants were saying.

\section{Data Analysis}

Initial strategies to collect data in an organized and systematic manner aided in developing the plan to analyze data (Marshall \& Rosman, 2016). Techniques recommended by Creswell (2009), Seidman (2006), and Smith et al. (2009) informed my data analysis process. First, because I also experienced the phenomenon being studied, I documented my own experience; this is discussed in my research positionality section 
later in this chapter. This process helped me better set aside my lived experience in order to focus on the participants' descriptions.

The interview transcripts served as the primary data source for my study; my ongoing journal served as an additional, but minor, source of data. Although Yin (2014) recommends that multiple data sources strengthen case study research, it is not uncommon for interviews to be the primary form of data collection. My reflective journaling was reviewed continually and served as a check and balance of my interpretations of the interviews over time, from person to person. The entries helped me analyze the interview transcripts by allowing a review of my thoughts at the time of each interview.

As I reviewed the transcripts, I occasionally returned to the original recording to check for areas that were not clear to the transcribing service. I then began coding each transcript, using Creswell's (2009) eight step method as a guide, also using horizonalization by listing significant statements as I reviewed the transcripts (Merriam, 2016). I reviewed the transcripts multiple times to get a sense of the whole. I then went back to my first interview transcript to begin a deeper review and search for what and how before proceeding to do the same with the other transcripts. As I reviewed the transcripts, I began highlighting statements that stood out and exemplified the participants' experiences, assigning them a code. I kept a list of emerging codes, then clustered similar ones together.

Next, I identified the most salient codes and categorized them, looking for ways to reduce the total number of codes. After, I determined which codes to use, based on those that were most prevalent, and organized the segmented evidence by category or 
theme. Finally, I reviewed the data again to ensure I captured the appropriate codes, categories, and themes. The themes were comprised of direct quotations from the participants, using their own words to reflect their individual experiences. Collectively, the themes created a composite description of the case (Creswell, 2009).

\section{Researcher Positionality}

My interest in studying this phenomenon is undoubtedly related to my own experience. While serving as the vice president for enrollment management at a small private college, I attended a webinar to explore possible options for changing our viewbook. The webinar introduced me to a complete CRM and marketing platform solution that could substantially improve our workflow and communication to prospective students. Although I was interested in adopting this solution, it was a significant investment and not a decision I could make on my own. As I explored the solution further, I began to involve others on campus who would be key to embracing this decision and having a successful launch if selected and purchased. Although it was frustrating at times, I had to navigate the politics of the campus, involving marketing, information, and technology staff. After nearly 3 months, we decided to purchase and launch the Enrollment Marketing Platform (EMP) and saw increases in entering class sizes for the next 3 years. Although we cannot definitively credit the EMP for the enrollment growth, it appeared to play a primary role in our new enrollment patterns.

About a year and a half after my initial introduction to the EMP, I left the college and began working for the EMP company as an educational consultant. As I joined the sales team on calls with prospective clients, I began to recognize aspects of my own experience in others. Our champions on the call would explain how they needed us to talk 
with marketing, or their information technology team, or help them determine how to reallocate funding to pay for the solution. I started to hear consistent responses: "I have to talk with my IT department," "my marketing team will need to buy into using the tool for outreach," "the president needs to understand the value," and "my team is comfortable with the current process." Closing a new deal could take up to 6 months, sometimes even a year. As a result of these experiences, I began to ask myself, "when we have someone so positive about the opportunity and excited to adopt it, why would it take so long to make the decision?"

I became curious about the experience of the champion who was interested in the solution. What was it like for them as a leader on campus? How did they build coalitions on campus to get a decision made and set up a successful implementation? Who did they need to involve on their campus? How many people did they work with and what was the dynamic between them and others on campus who needed to embrace a new solution? Who had the power to influence the decision both financially and administratively? How would they describe their experience within the context of a leader influencing change and navigating politics? Is there something for other enrollment management leaders to learn from these experiences?

My previous experience as a leader in enrollment management influenced my interest in the current study. It also allowed me to connect with current enrollment management leaders in a very personal and professional way. Participants were current clients of my employer. It was possible I had previous contact with some of the clients being interviewed, but due to my role with the company, I do not directly sell to potential clients or serve as an account manager. My relationships with the clients vary as the 
account managers and sales team bring me in to consult as needed. I was honest with each participant around my own experiences in order to establish boundaries for trust, expectations, and confidentiality. My experience in higher education spanned several different functions - student services, residence life, auxiliary services, and enrollment management - for over 25 years. These experiences, as well my own leadership experience in selecting and purchasing of the EMP, allowed me to relate to the participants thus establishing trust and openness. Sharing my positionality with readers is one technique to enhance trustworthiness; I discuss more about trustworthiness in the next section.

Based on my own experience, I had the assumption that other leaders who led the process of adopting the EMP had similar experiences; however, I was open to the possibility that they may have vastly divergent experiences. As the adoption of any new technology results in some type of change in process, I assumed these leaders found themselves leading change by establishing urgency and forming relationships with key stakeholders on campus to advocate for resources and buy-in for new technology adoption.

\section{Trustworthiness}

In qualitative studies, it is important to establish trustworthiness, as compared to quantitative studies where the focus is on validity and reliability. Marshall and Rossman (2016) compare quantitative research design with qualitative in a few ways. Most important, qualitative researchers usually do not conduct experiments that show cause and effect, nor do they use large numbers of randomly selected participants. Unlike in quantitative studies, the researcher is considered the instrument and seeks depth in 
understanding participants through relationships. Thus, validity and reliability of the instruments and data are not appropriate for qualitative research, rather the focus is on the credibility of the researcher and ensuring that data interpretation is "trustworthy" (Marshall \& Rossman, 2016). Researchers often refer to four concepts to replace the quantitative approaches related to internal validity, external validity, reliability, and objectivity (Lincoln \& Guba, 1985; Merriam \& Tisdell, 2016). Lincoln and Guba originally called these truth value, applicability, consistency, and neutrality. In the early 2000 s, researchers began to refer to these concepts as credibility, transferability, dependability, and confirmability.

To establish credibility for my research, I conducted member checks. Each participant was sent a list of the direct quotes being used and were asked to review and make any corrections. One participant asked for clarification on his quote and context, which was reviewed and adjusted to reflect his position. Member checking is considered a viable strategy (Creswell, 2009; Marshall \& Rossman, 2016; Merriam \& Tisdell, 2016). I addressed credibility through peer examination. My dissertation committee served as one check for credibility; a fellow former graduate student, familiar with qualitative research, also reviewed my findings.

Transferability of the findings is usually the burden of the person who wants it transferred, with the responsibility of the researcher to provide sufficient descriptions to allow the reader to do this (Merriam \& Tisdell, 2016). I provided what is referred to by many researchers as thick description (Creswell, 2009; Marshall \& Rossman, 2016; Merriam \& Tisdell, 2016). Thick description requires me to be highly detailed in regard to participants and the findings. To ensure thick description, I included many direct 
quotes from my participants along with details from each interview and the data analysis process.

Dependability, the third construct initially developed by Lincoln and Guba (1985) serves the purpose of ensuring the results are consistent with the data collected. Unlike quantitative research, where the question is if the results can be replicated, qualitative studies strive to focus on the alignment between data collected and the results being shared. It is unreasonable to expect a study with humans would have the same result if replicated because human being behavior is not isolated (Merriam \& Tisdell, 2016). One method used to facilitate the consistency between the data collected and the findings is to create an audit trail. The audit trail is a detailed documentation of the methods used by the researcher and should thoroughly explain how they ended up with the conclusions shared (Lincoln \& Guba, 1985). I kept a research journal during my study to log each process and decision made so that if needed, I could provide the additional detail about my research process.

The fourth construct to consider as part of trustworthiness is confirmability. Other strategies I described previously contributed to the confirmability of my research. These include the audit trail, member checks, and having an outside peer reviewer. Additionally, my position as the researcher is acknowledged as one that may influence bias in my interpretations of the data. Using the process of epoche, I sought to understand and bracket my own experience before interviewing the participants about their experience. It was important for me to not only reflect upon my own experience in order to set it aside, but also to be open and honest with the participants and demonstrate my own integrity in following the methods as planned. 


\section{Limitations}

All studies have limitations, as does this one. Case study research is bound by a "time" period and a specific defined situation, or "phenomenon." These allowed me to focus on obtaining detail from participants and complete the study, but also limited the scope of the study in terms of participants and experiences. My research intentionally

focused on leaders who worked at small, private, undergraduate institutions, because, at the time of the research, such schools have been struggling the most with enrollment. Leaders responsible for student recruitment at public schools, larger schools, and graduate-focused programs, may have something different to offer in terms of their experiences in seeking new technology.

Also, although none of the participants were clients with whom I worked directly, my employment at the company that sells the technology may have influenced how participants responded to me, including whether they agreed to participate. I used techniques to enhance my trustworthiness, but I may not have been able to mitigate participants' perceptions of me and the company in which I work. Additionally, a plethora of technology to aid in student recruitment is available to leaders. I recognize that by focusing on one specific technology, readers at institutions that use other technologies may not find this study transferrable to their settings. The EMP is often compared to other CRM technology available, and the process by which leaders explore and adopt these options may have expanded the participant base and experiences could have been different. The limitations of the study are further addressed in chapter 5 as I share opportunities for additional research. 


\section{Conclusion}

Leaders in higher education enrollment management are often faced with the significant challenge of maintaining and increasing enrollment. To effectively compete in this market, leaders often turn to adopting new technology to support their efforts in outreach and recruitment. The process for securing new technology puts the enrollment management leader in a position of leading change and navigating politics on campus. This chapter described the methods used to better understand the experience of these leaders in adopting new technology. I introduced the data collection process and the analysis used to capture rich descriptions that created the essence of the experience. I also presented strategies used to strengthen the trustworthiness of my study. In Chapter 4, I present the case, informed by the emergent themes from the data. In Chapter 5, I answer the research question and consider the findings through the conceptual framework informing the study. I also discuss conclusions and implications for practice and further research in Chapter 5. 


\section{CHAPTER 4: FINDINGS}

In this chapter, I present the findings of my study. The chapter begins with a brief overview of the participants. Next, I introduce the four salient themes that emerged from data analysis.

\section{Overview of Participants}

As indicated in the previous chapter, I interviewed 12 higher education leaders. All participants self-identified as champions who led their institutions through the process of exploring and deciding to purchase new technology to recruit students. The participants were at either the director or vice president level at their respective institutions; six held the title of vice president, five held the title of director, and one was the chief enrollment officer (CEO). Reporting lines varied slightly for participants. The six vice presidents and CEO reported directly to the president. Three of the remaining participants reported to a vice president, and one reported to an executive director.

Although four of the participants did not report directly to the president, three of them did serve on a president's council. The amount of time each participant had been in higher education ranged from 6 to 35 years.

All 12 participants I interviewed had experience in higher education and college admissions. As a result, they indicated that they had a sense of how people, processes, and systems worked for college recruitment. Two had experience at only one institution. One of them had been at the same institution but worked in admissions then held a role outside of admissions before he was asked to return and examine processes within the enrollment management office. Ten participants had worked at other institutions, in some cases several institutions, allowing them to bring an experienced and external view to 
their current challenge. Ten participants had previous experience in exploring and/or selecting new technology, with some leading the process; most participants' previous experience was through committee membership. The combination of experiences with admissions, working at different institutions, and previously exploring new technology within higher education positioned participants with the backgrounds to identify problems in their current circumstances that led them to champion adopting new technology.

Ten of the participants were new to the institution in which they were employed at the time of the decision to adopt the EMP, and one was new to his position, but not the institution. Only one participant had been at their school over three years when they made the decision to adopt the EMP. For the 11 who recently had been appointed, being new prompted them to begin assessing their new environment and identifying specific problems. Three of these 11 participants, Brett, Sean, and Jose, had been at their institution about 2 years when the decision to adopt new technology was made, but all shared they had recognized the need for new technology upon starting in their position on campus.

Six of the participants who were new to their school or position were specifically asked by the president to assess the current enrollment management function, or overall operations at their school. All six of these leaders were seasoned in terms of higher education experience, process improvement, financial management, and/or business practices. Three of these participants were brought to the school and position by a new president. One was appointed from within by a new president, and two were brought to 
the school by the current president. Below, in Table 1, I provided additional information about the participants.

Table 1

Participant Information.

\begin{tabular}{|c|c|c|c|c|c|c|}
\hline Name & School name & Title & $\begin{array}{c}\text { Reported } \\
\text { to } \\
\end{array}$ & $\begin{array}{l}\text { President } \\
\text { 's council }\end{array}$ & $\begin{array}{l}\text { Time in } \\
\text { position }\end{array}$ & $\begin{array}{c}\text { Years in } \\
\text { higher } \\
\text { education }\end{array}$ \\
\hline Harvey & Green University & Director & VP & No & 1 Year & 6 \\
\hline Jose & Maroon College & Director & VP & Yes & 2 Years & 25 \\
\hline Franklin & Yellow College & Director & VP & Yes & 18 Years & 18 \\
\hline Brett & Gray University & VP & President & Yes & 2 Years & 28 \\
\hline Vince & College of Red & VP & President & Yes & 1 Year & 23 \\
\hline Nate & Blue College & VP & President & Yes & 1 Year & 14 \\
\hline Lee & Orange College & VP & EVP & Yes & 1 Year & 12 \\
\hline Don & Royal University & Director & President & Yes & 1 Year & 8 \\
\hline Phillippe & White College & VP & President & Yes & 1 Year & 14 \\
\hline Helen & Gold University & CEO & President & Yes & 1 Year & 35 \\
\hline Sean & Brown College & Director & $\begin{array}{l}\text { Executive } \\
\text { Director }\end{array}$ & No & 2 Years & 7 \\
\hline Maria & Violet College & VP & President & Yes & 1 Year & 10 \\
\hline
\end{tabular}

In the remainder of this chapter, I present the themes that emerged from the data that comprise the case, or phenomenon. Through review of the interview transcripts and my journals written throughout the data collection period, four themes emerged that organize the findings. These themes are identifying problems, impetus for change, 
involving others, and influencing others. Subthemes are also shared within these broader themes.

\section{Identifying Problems}

Most of the participants described some type of problematic process or concern they had identified that diminished their ability to successfully recruit students. Some had walked into a situation where someone else had already started to recognize a problem or potential problem, and thus were charged to further investigate. Others identified concerns as a matter of course in their responsibilities related to how to get better enrollment results. The people new to their position had either been directed to examine their situation or naturally took it upon themselves as leaders to assess the overall student recruitment operations. Nearly all of the participants discussed problems they saw with general inefficiencies, poor communication with prospective students, or both, and believed a CRM would help solve those problems.

\section{Inefficiencies}

Participants recognized flaws in work flow, processes, information management, and data collection. These inefficiencies were often attributed to outdated or inappropriate technology used on their campuses. For example, Harvey had been an avid user of several different technology platforms at other institutions and quickly recognized the inefficient systems at Green. Upon his arrival, Harvey said it was clear to him that they were using a product that was very inefficient and ineffective. He noticed the work flow consisted of manual processes that created piles of paper and a back log of data entry items. The manual processes were in place because the team did not have 
technology that could automate; the team was doing the best it could with existing tools. However, those tools limited the potential for greater success.

Other participants also referenced the outdated technology and the need to be upto-date. Nate referenced getting the college "into the $21^{\text {st }}$ century" with technical services in a meeting with the president early on in his position. Nate determined "all of our systems were antiquated. We were still doing manual data entry for applications, prospect cards, etc." Nate had identified processes that were time consuming and causing additional work due to system limitations. Likewise, Helen mentioned the need to modernize the technology. She stated "...one of the imperatives was that we bring the college forward to present day, and lot of that was going to rely on developing new technologies..."

Brett's concern with the technology at Grey was that it had not been updated with new interfaces, and also that it was not easily accessible to the team. Brett shared:

It was just lacking in some of the more current technology access. There was no integration with chat, or internet web pages, or any of those kinds of things...the other piece for me was our only access to the system was if you were on campus or you VPN'ed in. And so, it had all been built pre-cloud-based computing. Despite the system challenges, Brett had previously used the technology being used at Grey and knew how to manipulate it, which allowed him to wait a year before pressing campus leaders for new technology.

Nearly all of the participants said their schools were attempting to use their main student information system (SIS) for student recruitment. Lee indicated that system worked well for academics and other college functions, but not for admissions. Lee said 
“...it really wasn't serving the needs to - provide our admissions team with the tool they need to stay in touch our students and be more effective in reaching out to them and filling our classes." Helen and Sean also recognized the technology at their schools was designed for main college operations, not for student recruitment, yet that was all they had. Like Brett shared above, Sean said he was familiar with the system because he had used it in a previous position. Because of his familiarity, he also recognized its limitations. He stated:

...they did not have a CRM program. Jenzebar [the student information system], although it managed the students, it was not a true CRM with all of the, let's say bells and whistles to track the enrollment process, figure out as far as do some predictive analysis, track my accounts.

Tasked with putting together an enrollment plan as part of an accreditation self-study report, it was important for Sean to have not only the plan, but also more appropriate technology to help implement the plan, which served as a driver to push for change.

Lee and Helen discovered their teams did not even realize there was a more efficient way to do their jobs. Coming from other schools using more advanced technology, both identified the inefficiencies their teams had accepted as the status quo. Lee shared that the college is continuing to grow in several different areas, thus prompting the need to do things differently. He shared that they recognize a need to do things differently in order to grow, but some of their team have been doing things the same way for 20 to 30 years. Similarly, Helen shared: "And the individuals in the offices that reported to me were not even aware that such a tool existed, so they weren't looking for anything." As a result of the lack of experience and exposure to newer technologies, 
Helen's team were doing more manual labor than necessary. This was even more evident because she had used new CRM technology and understood the economies of scale that could be created with it. Thus, she knew she needed to move the school forward in developing more efficient student recruitment practices.

Phillippe said her primary challenge was in obtaining information to help inform decisions. As she was seeking information on campus to help get to the root of the enrollment problems, she discovered there were not a lot of data available. People were talking about things that were being done, but there was no system tracking any of it, or helping to measure results. She shared that she needed to identify:

what kind of different systems or consultants might help us design something that ...would create some sort of ethos or platform or something where we could gather this information... and measure what counselors are doing. Measure what prospects are doing. And understand a little bit better what's landing.

She summed it up by stating "But what we really needed was that place - that tool that would help us organize what we were already doing in a haphazard way." Phillippe had identified that their lack of technology was creating problems in both organizing processes and providing data to help the college analyze effectiveness.

As some participants reflected further, they described how these inefficiencies in process led to ineffective communication with prospective students. In some cases, finding out students were receiving irrelevant information or that staff were not able to track progress on their outbound communication, was the driving force behind discovering the lack of a good plan and system. In both cases, identifying the problems of inefficiencies in process and ineffective communication created some of the impetus for 
changing technologies. Next, I share how participants specifically talked about the problem of ineffective communication.

\section{Ineffective Communication}

A few of the participants identified problems related to the ability to effectively communicate with prospective students. These problems included the delay in responding to interested students, the lack of tracking capabilities for electronic communication, and outreach not being targeted and relevant to each student. To begin, the delay in getting information out to students was a problem for many, often the result of the manual processes such as exporting lists in excel and doing mail merges with Outlook or using a third-party email service. Keying information into a system manually also resulted in a delay in getting communication out. This was particularly true for Harvey, who described the amount of data to be entered as nearly 3 feet tall. Jose shared that there simply was no electronic communication sent to students, so they had to wait on a mailed print piece. Similarly, Nate discovered the antiquated technology at his college was creating additional workload for staff and resulted in an "unacceptable delay" in responding to prospective students.

Some participants cited the inability to communicate across multiple channels, such as print, email, and personal microsites, as well as the ability to accurately track electronic messages as a problem that limited the colleges' potential for more applicants and enrollments. For Phillippe and Sean, there was simply no tool to help manage an overall communication plan. Both knew the importance of communicating with student prospects and their families across multiple channels but did not think they had the tools in place to do so efficiently. They also found that there was no comprehensive 
communication plan on their campuses, nor a way to manage such a plan if one was developed.

Brett described another example of the limitations participants encountered as a result of existing campus technologies. As part of an enrollment campaign, his team sent out electronic messages to students, but could not track student communication reliably. The existing campus email system could not track deliverability of emails or open rates to give them a sense of how the campaign was performing. Prior to Jose's arrival, the school had only been using a print viewbook to hand out at recruiting activities both on and off campus as well as to mail to students requesting information. There were no other channels used to reach students, much less track any of it.

Without a dependable communication plan and system in place, participants relied on generic blast messages to students rather than personalized communication that would be directly relevant for each student. Because of Vince's previous experience, he used other systems that were automated, personal, and trackable, so knew there was a better way to manage communication. Harvey reported that his campus communicated electronically, but the communication did not always target students appropriately. He shared:

Literally, if you are communicating with your inquiry audience this become very problematic because if you want to push applications, it's insulting when you say, "we need you to apply," and the kid has done it or if they're even admitted or deposited even, and we are talking to them like they are an inquiry. That was offensive to our audience. 
Harvey also lamented that there was not a good way to identify duplicate students in the system, which resulted in communications being sent to the same student twice, or worse, different communication to the same student depending on the information within each duplicated record.

Brett was also concerned about the lack of personalized communication. $\mathrm{He}$ shared:

...I definitely wanted to find an opportunity to develop more personalized communication with students. That's critical, especially being a small institution where we talk a lot about the students being known, and being valued, and that they are an individual, not a number. I wanted that to be reflected in our recruitment communications from the very beginning...

Brett specifically mentioned he was interested in the personalized web pages that were customized to each student and helped them feel like they were already a part of the school. To do so, he believed new technology was necessary.

The identification of these aforementioned problems and the knowledge that there were ways to solve them was part of what drove the change each leader pursued on their campus. For a few of the participants, the problems served as the initial impetus for change, and for others it was part of continuing a nascent change initiative. The next theme, impetus for change, describes the initial impetus for the change on participants' campus and their role within the change process.

\section{Impetus for Change}

Each of the leaders I interviewed went through a change on campus with the purchase of a new CRM. As described above, the leaders identified problems related to 
their existing enrollment strategies and processes. The current theme narrows in on the principle impetus for changing the existing enrollment practices on their campus. In some cases, the impetus for change was initiated prior to the leader arriving on campus and/or assuming their role, which meant that the change process may have already been initiated. For example, many of the participants were new to their campus, and some of them indicated they had been put in their role because of events or situations calling for change. As these leaders assumed their role, they continued to assess the people, processes, and systems, and further recognized more specific needs for change. Others were not necessarily hired as part of a need for change, but once in their positions they quickly made discoveries that prompted the need for change.

Two categories fall within the theme impetus for change. The first category, initiated by others, describes the situations in which the impetus for change was initially driven by someone other than the participant. The second category, self-initiated, reflects the situations in which the leader identified the need for change on their own, and did not identify any other impetus for the change to occur. For those situations that were driven by others, the leader escalated the need for change once they identified additional ineffective and inefficient systems and processes.

\section{Initiated by Others}

The majority of participants described situations in which it appeared someone else had recognized a significant enrollment management concern and started to plan for a change. In fact, employing the leader was often a first step in advancing the change agenda. In those cases, leaders were told that the broader problems that led the campus to bring in new leadership included not making budget, employee reductions or turnover, 
enrollment declines, the lack of adaptation from moving to a 4-year school from a 2-year school, and changes in campus technology that eliminated the system being used for recruitment.

Two participants specifically identified budget shortfalls, including one case in which staff reductions occurred to mitigate the shortfall, as the primary reason for the need to change existing processes and practices. When I asked Don what prompted him to begin the search for new technology, his response began as "nothing works quite as well as necessity." The president internally appointed him to his leadership position and asked him to determine how to reduce staff size and also bring in new students. He further explained the situation at Royal:

What forced the conversation with trying to find a CRM or marketing platform that allowed for all the things that this one provides as far as automation and personalization without relying on manpower. It was a very forced exploration for us...We had to cut people immediately and we had to find solutions that could take the place of those people.

Phillippe also cited budget as the impetus for change on her campus. Her position was different from my other participants. She was hired as the chief financial officer and was specifically asked to examine overall business practices at White College. Phillippe quickly recognized they were not going to make their projected revenue and understood the importance of enrollment to meet tuition revenue. This meant inserting herself into the process of recruiting students, which led her to discover the lack of a comprehensive strategic enrollment plan and data that indicated a downward spiral in enrollment if something was not done to change how they worked. In her case, it appeared the 
president recognized there was a larger budgetary problem but did not hone in on enrollment matters. Thus, in her case, the original impetus may have been the president recognizing a need for change more generally, followed by Phillippe's discovery that the revenue goal was not going to be met and that better enrollment management could be part of the solution.

Phillippe and Jose both shared that their institutions had previously been 2-year colleges but had been offering 4-year programs for several years. The change in the campus mission happened prior to their arrival at their respective institutions and neither campus adapted processes and practices to accommodate this change. White College had experienced some initial enrollment increases when it began offering 4-year degrees. However, Phillippe reported that the increase was due to students continuing on to complete their bachelor's degrees rather than an increase in new first-year students. Soon after her arrival, she was tasked with presenting a plan to the board outlining how the school was going to be "weaned off" their current resource pool and into a break-even situation, which required a net increase in new, not continuing, students. Like Phillippe, Jose said Maroon was "behind" in adapting their recruitment strategy even though it had been 14 years since the campus moved to offer bachelor's degrees. Although the move from a 2-year to a 4-year institution may not have been the primary impetus for change, it was worth noting that two participants described that it likely contributed to the situation.

Three of the participants, Nate, Helen, and Maria, were specifically charged with updating technology on their campus upon being hired. None of the three shared details around what actually prompted them to be asked to address existing technology, but it appears the impetus for change began prior to their arrival. Each of these participants 
identified that the technology on their campuses was either outdated or not intended for student recruitment. Their assessments reinforced the need for change seemingly identified prior to assuming their positions, which ultimately led to the adoption of new technology. Maria shared his recollection of starting at Violet:

...I came in with the new president...he asked if I could have three to six months to interview people that I've worked with and worked for me and just do kind of a position review and reshape our team and then buy a software that be more conducive to enrollment growth.

These three participants shared being specifically tasked with looking for new technology as part of their complete assessment of the overall operation of enrollment. Their hiring was part of the impetus for change that was initially identified by another campus leader, in most cases, the president.

Franklin explained that the implementation of a new student information system (SIS) across campus prompted the exploration for new technology at Yellow College. The new system did not provide the same technology capabilities to manage student recruitment as the previous system. The new tool did not allow the team to generate a competitive communication flow, which needed to be resolved quickly. Franklin was responsible for selecting a new technology to address the SIS's limitations, but he was given specific options from which to choose based on what would communicate with the SIS. He was prepared to select a particular system when he attended a conference and heard about the Enrollment Marketing Platform. This prompted a re-examination of the decision. The discovery of a new, potentially preferred option, served as the secondary impetus that ultimately led to the specific change to the EMP. His vice president allowed 
him to go ahead and explore this new option with his team, and eventually Franklin led the charge in purchasing and adopting the EMP.

For Sean, there were multiple factors he identified as the change drivers. First, his predecessor had retired, and half the staff left. Second, the enrollment at his campus had been declining in previous years. Third, the college was preparing a self-study for an upcoming accreditation site visit. He found himself rebuilding an admissions team and developing a plan to increase new student recruitment to share in the self-study report. It is difficult to ascertain which of these may have been the actual impetus, likely a combination of the declining enrollment and impending accreditation review were the primary drivers. All three factors represent the urgent situation Sean was in when he started his new position.

Lee at Orange College shared another example of others initiating the impetus for change. Although he was new to his position and said he immediately recognized the need for a CRM, he later shared that his predecessor had actually started the process of exploring options. Lee was asked to take the lead in this exploration, but also noted that his predecessor was still at the college in a different role. Lee did not go into detail as to what prompted the initial search, but made several references to their need for a CRM to improve overall processes of recruitment.

The common thread for each of these participants is that they found themselves responding to the need for change that others identified, often in light of dire campus circumstances. From the participants' stories, the actual or original impetus for change seemed to occur prior to their arrival at the institution or new appointment. But they were 
crucial in carrying out the necessary changes, and often were hired for that primary purpose.

\section{Self-Initiated}

In contrast to others initiating the impetus for change, some of the participants described their situation and drive for change as self-driven. Neither Harvey, Brett, nor Vince were specifically charged with changing technology. Unlike those in the previous subtheme, they also did not identify factors such as budget issues, enrollment declines, or other significant campus changes beyond their new roles on campus. All three ultimately cited the inefficiencies due to lack of current technology as the impetus for change.

Harvey identified significant problems in their processes. So much was done manually he figured out there was no way to catch up with the current staff resources and system. The piles of paper referenced earlier within the theme of identifying problems eventually became a significant factor in his push for change. After being told by his vice president to "work harder," Harvey discovered the reason that the school only had 5,000 to 6,000 inquiries entered for each cycle was because that was the maximum number that could be entered manually. He said:

It doesn't matter how hard we work; this is what we can get done in a year and it isn't efficient. It's not about people not doing or being lazy, it's about not having a system that supports doing what we need...I just said "this has to change. It's not acceptable. We can't sit back and allow it anymore."

Harvey was the clear driver and had identified the impetus for change himself.

Brett and Vince also assumed their positions and soon identified the need for change. Upon hiring, they were not asked to make any specific changes, but their natural 
process of assessing their situations led them to identify the need for change. Brett quickly determined that the existing technology was obsolete; it was not cloud based and thus not easily accessible for his team. He was able to make their current system work for a couple of years because he was familiar with it, and had a good data manager in place who could manipulate it. He knew, however, that this was only a short-term solution, and took the initiative to begin the search for new technology to improve their processes and communication. Similarly, Vince was not asked to identify new technology or charged with making specific changes, but he promptly identified inefficiencies and the inability to communicate effectively with prospective students using their current technology. Vince made it a priority to secure funding so that he could acquire new technology and advocated for incremental increases in his budget. His assessment of the situation, coupled with experience in using technology at other institutions, drove the impetus for change at College of Red.

In summary, the impetus for change drove every participant to act. Most were responding to something already in place due to necessary budget cuts, not making revenue goals, declining enrollment, or needs that had been identified by someone else that prompted a directive for the leader to further evaluate and take action. The leaders who did not cite larger institutional challenges, and who were not specifically told to take action, described how they identified problems, determining that change was needed, and taking the next steps in the change process. The next theme, involving others, illustrates how each participant described bringing others into their change process. 


\section{Involving Others}

The involvement of others was the third theme that emerged from the data analysis. Every participant described the involvement of others in their experience, with some variations on who was involved, when, and how. Table 2 outlines those other stakeholders who they involved throughout their process. Nearly all participants engaged marketing at some point during their change process. To provide more specificity beyond a simple yes/no as to whether the leader involved a marketing team, the table includes a separate marketing column that indicates the stage of the process in which the marketing team was first involved: never, early, later, and after. 


\section{Table 2}

Who participants involved and when.

\begin{tabular}{|c|c|c|c|c|c|c|}
\hline Participant & $\begin{array}{c}\text { Contacted } \\
\text { people outside } \\
\text { their } \\
\text { institution }\end{array}$ & IT & Marketing & $\begin{array}{l}\text { Down-line } \\
\text { managers }\end{array}$ & President & CFO \\
\hline Harvey & Yes & Yes & Later & Yes & Yes & Yes \\
\hline Jose & Unknown & After & Never & Yes & No & No \\
\hline Franklin & Unknown & Yes & After & Yes & Yes & Yes \\
\hline Brett & Yes & Yes & After & Yes & Yes & Yes \\
\hline Vince & Yes & Yes & Later & Yes & Yes & No \\
\hline Nate & Unknown & Yes & Later & Yes & Yes & Yes \\
\hline Lee & Unknown & Yes & Later & Yes & Yes & No \\
\hline Don & Unknown & Yes & Later & Yes & Yes & Yes \\
\hline Phillippe & Yes & Yes & Early & Yes & Yes & Yes \\
\hline Helen & Yes & Yes & Early & Yes & Yes & No \\
\hline Sean & Yes & Yes & Early & Yes & Yes & Yes \\
\hline Maria & Yes & Yes & Later & Yes & Yes & Yes \\
\hline
\end{tabular}

\section{Reaching Outside Their Institution}

Over half of the participants indicated they had reached out to people outside of their organization as part of their exploration process. Their outreach was done early in the process and did not serve the purpose of consulting references related to a specific technology under consideration, rather it was done early in the process to help determine potential solutions to explore further. Sometimes participant outreach included engaging 
colleagues within a specific peer group of institutions, as their needs were likely to closely align with those at their own college.

For example, Phillippe identified other independent colleges and began calling to see what they were doing to manage recruitment and what vendors were being used. Maria used a similar approach by identifying schools that were in a growth phase and were like them in terms of mission, target market, and programs. He reached out to see what systems they were using and inquired as to the strengths and weaknesses of each. He developed a list of seven or eight options to start his search for new technology using this process. Sean shared that Brown was part of a collective of other similar institutions and he started his technology solution search by connecting with them:

Brown College was part of a network, of a denomination that has several other universities as part of it. My first step was to connect with my sister schools around the country to find out what companies they were using, what the costs were, what were their experiences in launching them...

A few of the participants had either used the EMP when they worked elsewhere or were aware of it and reached out to users on their own. In addition to their own experience and information gathered previously, they still checked with other users to validate continued interest. Vince and Jose both were in the group of previous users who reached out to former colleagues. Brett had learned of EMP at a conference and identified other current users and reached out early on to get a sense of the system, service, and company reputation before proceeding.

Most often, participants described tapping into their personal professional network established over their years in the enrollment management industry. Harvey 
indicated he reached out to colleagues at other schools who worked with various systems. He shared that these were people he trusted and knew had a philosophy similar to his. Vince, who, as mentioned earlier, was familiar with EMP, did his due diligence by reaching out to his former colleagues regarding other options he should be considering or not considering. Helen reached out to a former colleague, but also contacted a couple consultants with whom she had previously worked to "pick their brain" before reaching out to companies directly.

\section{Involving Others on Campus}

Information technology. All of the participants except one involved their main campus information technology (IT) department at some point in the process. Most referenced this was done due to the need to ensure data could flow from the new system to the college's SIS. The one person who did not involve central IT stated he had an internal data manager who was capable of getting information into the main campus system. He did, however, involve IT after the decision was made. How and when IT was involved varied from person to person, spanning from being an equal partner in the process, to being told they just needed to make it work. Most situations fell in between these extremes, with the participants sharing they had notified IT early on, kept them informed throughout, and then brought them into conversations later to work out the integration.

Phillippe, who did not oversee the campus admissions function, said the campus IT person was her primary partner through the process. The two of them did their initial work without the vice president of enrollment to identify a system that could best help the college. She said: 
We vetted all of them first because we were sort of - I don't want to call us the fixers. We're the drivers on campus. So, if there's a problem and it involves money or people, it's me. If it involves something you plug in or a computer, it's him.

In this situation, the head of IT was a primary player in the selection of new technology. Once the two of them narrowed their choices down to three, they brought in the vice president for enrollment.

Brett described the experience with his IT colleague quite differently. He talked with her initially to be sure the files would transfer over into the SIS. Brett said she pretty much tried to lock down the campus and not let them do anything. She raised concerns about security when he approached her about looking for new technology, and Brett said it was challenging. He ended up pushing back and made a clear statement of his authority and plan to collaborate:

[I told her] we're not doing anything dramatically different as far as an IT interface from what we're currently doing. So, I want to make sure we feed you the data you need in the form that you need it but otherwise, this is our decision... I want to be a collaborative partner and make sure we get the data that we need and can work with the other, but I've got to make sure my team is able to be effective in what they need the software to do.

Brett shared he knew the IT colleague was going to be key to the success of adopting new technology. He notified her early on as a courtesy but needed to move forward with a system that would, first and foremost, meet the needs of his team to recruit students. 
The remaining participants described the involvement of IT somewhere in between these extremes. Unlike Brett, none shared any pushback from their IT teams, but involved them at different times in the process and in different ways. For example, Sean and Lee were working with teams or committees for their search for new technology and included IT on that team, along with other key players. Vince and Nate did not involve IT in their initial exploration of a new system, but brought them in once the choices were narrowed down. Don and Helen notified the IT person early on that they were exploring options to be sure someone could help make it work; however, he said IT was not a part of the final decision on what system would be adopted. Maria indicated his IT person was quite involved so that the new technology would communicate with other programs and software on campus. Maria shared "I leaned highly on him" when talking about the head of IT.

Not surprisingly, for nearly all participants, information technology professionals played a role in the exploration and selection of a new technology. Although the level of their involvement varied in the change process, all but one participant engaged IT at some point. Likewise, participants discussed how they included others in their units in the process.

Downline managers. Other than Phillippe, who was in a unique situation in her organization as the $\mathrm{CFO}$ who assumed responsibility for the change process, all participants, involved members of their team in the process, including directors, associate and assistant admission directors, and data managers. However, Phillippe understood that the admissions office needed to be included in the process and did include the vice president of enrollment management in the later stages of selecting the EMP. This person 
did not report to her directly but was technically responsible for managing the admissions function.

Three people discussed the involvement of the individual in their unit responsible for data management. In Jose's case, he involved his enrollment data manager because they would be the one working with the new system, and also would be responsible for getting the data into the main campus system. Having this person on the team is the reason Jose did not need to include anyone from central IT in making the decision about which technology to select. Brett and Sean also included their data manager in the process. In Brett's case, the data person was his primary partner in leading the exploration for new technology. Sean included the data manager at a later stage in the process, but their role was crucial. That person eventually became the primary contact for implementing the new system.

Four participants described bringing in people at the director level, usually the director of admissions or enrollment. Vince included both his director of undergraduate admissions and director of graduate admissions because their intention was to adopt the system for recruiting both populations. In Lee's case, the director served on his selection team, like the IT person. Others did not have formal committees or teams and brought in their directors by the time they scheduled demonstrations of the potential systems. Nate did not specify the level of people on his team he involved, he just indicated that "appropriate staff in admissions and financial aid" were invited into the process. He was the only participant who mentioned including financial aid staff. Helen was a bit of an outlier, in that although she had a director of admissions, she did not involve that person 
because they were "in flux" and ended up letting that person go. She did have a replacement hired who was involved during the later stages of the process.

Harvey and Franklin, who were both at the director level, brought in their direct reports at the assistant and/or associate director level. Harvey included his associate director of admissions early on in the process and described her as a veteran in the office who also knew there was a problem that needed attention. He wanted her perspective as a veteran and asked her what she thought about the potential solutions. Harvey also shared the search for new technology with his larger staff so that they were prepared for the change once everything worked out. Franklin, who reconsidered the campus's technology selection after discovering the EMP at a conference, introduced the EMP to his associate and assistant directors once he was given permission to explore it further. He began by sharing what he had found himself, then scheduled time for them to meet with the company representative and included them throughout the process going forward.

All participants involved people who reported to them, or in the case of Phillippe, the leader of enrollment management on campus, at some point during their process. The decision about when to involve them was strategic, and in the final theme, regarding influence, I describe their processes and why including people closer to the day-to-day use was important. In addition to including those who report to them, participants had to engage other campus leaders in their processes. Next, I discuss who they involved, and the level of their participation in the process.

Campus leadership. All but one of the participants indicated their president was aware of, or involved to some degree, in the decision to adopt new technology. Like with many of the other stakeholders discussed in this theme, the level of the presidents' 
involvement varied. In some cases, the president was responsible for hiring the participant who then had complete authority to make decisions; in others, the president was more hands-on and watched demonstrations of various technology options and made calls to other institutions to explore other possible technology options. It was common for the president to approve the budget or to refer the participant to work directly with the chief financial officer to allocate the funds needed to purchase the technology. The presidents' involvement was most often described as being collaborative and collegial, rather than as a challenge or barrier.

As mentioned previously, some of the presidents were the ones who had charged the participant who was leading enrollment management to improve processes or explore more updated technology options. Harvey knew the president needed to give final approval for the purchase but felt frustrated that he did not have direct access to the president, having to work with the vice president instead. Vince needed to convince the president to go with a solution that was not part of their main campus SIS, but never expressed receiving unreasonable push back. Maria recognized that his situation was a bit unique in that the president had given him "complete empowerment" to make the final decision. Brett and Don both were keeping their president informed, and were working with their chief financial officer to get funding either reallocated or approved to move forward. Jose, the one participant who indicated his president was not involved, was at a lower leadership level than most of the other participants. It is possible that he may have not known if his vice president had discussed the decision with the president.

For some participants, the process not only included the president, but also involved the campus executive teams or cabinets. For example, Nate personally involved 
his colleagues on the campus cabinet, inviting them to participate in demonstrations once he had narrowed the options down to three. He described the decision process as very collaborative, on which I will elaborate in the next theme. On Lee's campus, the cabinet approved budgets; as such, his committee presented a final plan to the cabinet. However, the cabinet was not involved until the solutions were vetted and one was selected and put into a comprehensive plan. In Sean's case, the cabinet was involved at two points with final approval coming from their board. The cabinet initially agreed to move forward with the exploration of new solutions and formed a committee to vet the options. Once the committee had made a selection, they had to present it to the cabinet who ultimately took the request to the board for final approval. Sean's school had experienced a significant decline in enrollment; thus, the board was particularly invested in the process and required a complete enrollment management plan with associated costs before the purchasing process could continue. Some participants had colleagues on the college leadership team who were responsible for marketing; others were directly responsible for marketing. Nearly all brought in marketing staff at some point during this process, which is discussed next.

Marketing. Each participant discussed how marketing colleagues were involved in their process, as well as where their marketing department fit into the structure at their school. About half of the participants said their marketing department operated separate from admissions, and many said they did not consider marketing to be directly involved in student recruitment marketing. The role marketing played on these campuses was general brand awareness for the school, managing the web pages, or working specifically with advancement. The marketing team for these schools was usually notified after the 
decision had been made to adopt the EMP, and some were never going to utilize the EMP but needed to provide branding standards for set up. For schools that did rely on campus marketing to help with recruiting students, participants involved them at some point in the process. In a few cases, marketing was brought in once the marketing capabilities of the EMP were discovered, and people saw how marketing could utilize these tools. Although marketing may have been included, it was apparent marketing was usually not involved in making the decision. Participants shared involvement of colleagues in academic units, who were also not always directly involved with the final decision. Next, I share who from academic areas was involved and why.

Academic units. Others within academic support units and departments also participated in many of the processes. Participants discussed the involvement of the campus registrar, academic deans, and faculty members. For most leaders, the registrar was usually included as part of the data transmission process, along with the information technology personnel. Nate brought in the academic deans, along with several others on the campus in order to "spread accountability" for the final decision. Maria included an academic dean as well as a "middle-aged faculty member" to help assess usability of the system and promote use by everyone on campus. In most situations, staff and faculty played ancillary roles in the technology selection and adoption, but participants often included them to support the change process.

No one went through the change process entirely alone. There were similarities in who the participants involved, with many reaching outside their own institution, all working with their information technology teams, and nearly all of them involving their downline key managers. All but one indicated that their president touched the process at 
some point, even though the level of presidential involvement varied. A variety of other positions and areas on campus were also mentioned by the participants, which included staff and, in rare cases, faculty in marketing and academic areas at different points during the process. The next theme reveals one common reason why participants involved different people: influence.

\section{Influence}

Participants involved others for a variety of reasons, such as soliciting input, checking to be sure new options would work with existing campus technology, and obtaining approval for funding. The scope of influence of various stakeholders informed participants' decisions about involving the people they did. Not only did their influence matter, but the participants also used influence as a tool in the change process. I often heard the terms "impress upon," "buy-in," "selling internally," and "convince" used, which reflect influence. Participants explicitly mentioned that influencing others was a component of the process. Influence was used not only to get a decision and funding from the president and cabinet, but also to prepare their teams and others on campus for change.

\section{Influencing Leadership}

Nearly all the participants had to spend time influencing people in leadership positions above them in their organizational structure and/or other people in leadership roles on campus. This included direct supervisors, presidents, cabinet members, academic leaders, and sometimes governing boards. For example, Sean and Harvey were in similar situations, as neither reported to the president or served on the cabinet. Both had to work through their direct supervisors to influence people at a higher level. Harvey expressed 
frustration in this process because he reported to the vice president, who reported to the president. Harvey mentioned several times that he did not have a "seat at the table" and therefore needed to work through his vice president to advocate for change. He shared the process:

...so I had to impress upon my boss the need for this...I had to do a lot of work to get the value across, show the needs, and get him to look at our systems and look at what we were doing and push his nose into it, so to speak...I worked very hard to help him understand all the issues we were facing...made him look at stuff and say "here's this three-foot pile. Do you believe that's a problem? We're missing these students."

Harvey acknowledged that bringing the vice president on board was imperative, stating that without his support the change never would have happened. He said his biggest challenge was "trying to be persuasive and firm and show a level of trust" in influencing his boss to advocate for the new system.

Sean also had to work through a middle person and was in a unique situation. He reported to the executive director, who was also the president's wife, so she reported to a vice president who reported to the president. This meant the enrollment area was not directly represented on the cabinet. Sean said, "that was a challenge because every vice president had their agenda...even though we were under the vice president of academic affairs, his priority really was for faculty, more on the academic side as opposed to the enrollment side." He spent a year pitching a plan and details from companies but said he kept getting pushback. He described his actions during that year: 
...I had to work politically to try to educate, inform...basically, asking questions, drawing - primarily informing the leadership and working through the VPs. I also worked with faculty to try to get buy-in to what I was trying to accomplish. Faculty had a lot of influence at that college.

Nate, Vince, and Lee all shared their efforts to advocate for budget approval. Nate brought in the business office early and felt it was important in order to secure the necessary funding: “...typically the president and finance office are very close and tight. At every institution I've worked at - you've gotta work through one of them to get what you need in terms of funding." Vince said his biggest challenge was convincing the president to approve an incremental budget increase when their school had limited resources. The president needed help understanding why SIS currently in place could not be used, or why an add-in available through the same provider was not an option. Vince spent time helping the president understand the complexity of using the enterprise system for student recruitment. Similar to Vince's education of the president, Lee needed to be sure the cabinet members understood, and that the larger campus community bought into the technology before the cabinet would approve the financial resources. Lee spent time negotiating with the company to develop a solid package, then pitched the proposal for budget and assured the cabinet of the buy-in across campus.

Participants reinforced the importance of buy-in among various constituents in order to move the change process forward. Nate and Maria discussed working with other campus leaders and how it was important to get "buy-in" and spread accountability. Nate appealed to individuals based upon the different roles they played on campus. He would direct his message, emphasizing different benefits of the technology, to a particular 
audience. For example, he might introduce how it would improve service to students, how it would integrate with the enterprise system, or how it would support the campus efforts to move from paper processing to electronic processing. He also involved the academic deans and pitched the idea of an easier application review process. Nate shared: ... as it relates to the academic units it was creating buy-in from them that "Hey, we're going to move away from paper processing to automated processing to allow you to review candidates in the comfort of your office, your home wherever you have a laptop or PC you could access this data." Maria involved a variety of leaders throughout campus who he needed as advocates because their teams would use the system. He wanted everyone to assess usability and envision processes that could be put in place with the new tools. The most important factor, however, was buy-in. Maria shares:

But the big thing for me was buy-in from the decision maker, so that's why I wanted the athletic director and academic dean there to say "okay, I see that this is easy to use, I will enforce those direct reports in my area to use it."

Influencing people in leadership roles across campus was important, in part, because they were able to influence others to support the decision to select and purchase a new technology. Participants did not only influence up, but they also influenced people on their recruitment teams during the decision-making process. Examples are shared within the next section.

\section{Influencing Their Team}

Most of the participants were savvy leaders who knew the importance of getting their internal team members on board for change. The importance of involving and 
influencing campus leaders was often the leader working with peers or people in positions above them. It may have been possible for them to simply require their direct reports and teams to use the EMP once it was purchased, but most described involving their team members and working to influence them.

Three of the participants shared examples of how they worked with individuals on their team to influence and encourage them. Harvey said there was some initial apprehension from the front office staff, who he said felt that they had job security because of their manual work. Adopting a system that could automate much of this work meant they felt less valued for their contribution. Harvey describes how he handled this situation:

...for me, you have to reaffirm that people aren't losing value in their work because have a new system that helps us get better and faster. You have to show people their value has everything to do with how they work together.

He spent time at staff meetings addressing concerns people had, and also was sure to discuss the potential change during his weekly individual meetings with each team member. Brett included his main data person throughout the process, and said at one point this person became a bit apprehensive. A new system would change the way he worked, and he was quite proficient with the system in place. His hesitation was eventually turned into excitement to learn something new and the potential change boosted his sense of value to the institution. Brett described how he helped turn hesitation to excitement:

I did, yes because I knew he was going to play a critical role in how effectively we were able to transition. And I needed to make sure we didn't lose - anytime 
you make a significant change to a system or structure, you are at risk of losing momentum and I knew we couldn't...It was important to make sure he was coming along well with the process.

Brett knew the importance of keeping his team member excited about the change, so they did not miss a beat during implementation.

Nate also shared an example of working with one particular person in his office to get her support. The supervisor for operations was responsible for all the data management and was nervous, even "panicked" about the change. Nate took time to be very encouraging and positive, as he recognized her importance to a successful implementation. He shares:

...She was the longest tenured staff member in the office of admissions. Everybody else had been there a shorter amount of time and they looked up to her for situations and issues such as this - and valued her opinion.

Nate recognized her importance to the success of the project, but also her ability to influence others in the office as they prepared for change.

Other participants cited the importance of getting their teams on board and making sure they felt they were part of the decision versus being presented with a mandatory change. Vince was clear that the involvement of his two directors of admission was to garner support for a new system: "So obviously, you need a buy-in from each of those members there. So, part of that exercise, make sure I had buy-in with that, and I absolutely did."

Jose also saw the importance of involving his team. He involved his recruitment staff and enrollment data manager in the early conversations. He wanted them to see the 
value in the tool and not just something he thought they should adopt. Jose shared: "I didn't want it to be something where it's just Jose thinks this is cool so let's give it a try...I wanted to make sure that the staff saw this as something that would be beneficial as well." Like Vince and Jose, Don recognized the importance of "selling internally" and brought in admissions counselors who would be the front-line users of the EMP. Don was in a challenging situation due to immediate staff cuts, making their support particularly critical. He said to introduce a new system “...we had to make sure that everybody on those teams were onboard."

Involving team members could have been a coercive process, but these leaders described how they engaged and influenced their teams in a positive and productive way. Many referenced the important role their team had in helping understand the need for a new system and how it would shape their work moving forward. Involving key players early on, recognizing the internal influencers, and taking time to encourage and reassure people were all strategies shared by the participants as part of their work with internal teams.

\section{Summary}

In this chapter I presented the findings from my data. I provided an overview of the participants, their positions, and their circumstances. Four main themes emerged around how participants described their experience in selecting new technology for student recruitment: identifying problems, impetus for change, involving others, and influencing others. These themes provide the insight needed to answer the research question for this study. In the next chapter, I answer the research question, using the 
frame of early stages of change management. Implications for practice will be shared, along with opportunities for further research. 


\section{CHAPTER 5: CONCLUSION}

The purpose of the study was to understand the case of how leaders in enrollment management described their experience of establishing urgency and creating coalitions as they led the selection process of adopting the Enrollment Marketing Platform (EMP) technology for the primary purpose of recruiting students. In this chapter, I summarize the findings of the study, answer the research question, and connect the findings to the theoretical framework and related literature. Finally, I share implications of my study for practice and for opportunities for future research.

\section{Summary of Findings}

The primary data source for my study emerged from interviews with 12 leaders in higher education who championed the process of selecting new technology for student recruitment. The leaders were all at small, private institutions that heavily relied on undergraduate enrollments, and thus, undergraduate student recruitment. Each considered themselves the champion in leading change on their campus to adopt the EMP, a system with CRM functionality to improve the process of recruiting students.

As shared in the previous chapter, four themes emerged in the data analysis: identifying problems, impetus for change, involving others, and influencing others. These themes collectively describe the experiences participants had in leading change, rather than the technical aspects of the change. Below, I interpret the findings to answer the research question. Before doing so, I reintroduce the profile and role of the participants, particularly in light of the extant literature. 


\section{Participants and Role in Enrollment Management}

The profile of the participants in this study is consistent with the positions and responsibilities described throughout the enrollment management scholarship. Most of them were in the formal position responsible for enrollment management that became common by 2004 (Schultz \& Lucido, 2011). Their scope of responsibility typically encompassed functions that included financial aid, admissions, and marketing (Hossler, 2015).

Over half of the participants reported directly to the institution's president, and all but two served on the president's council. Many colleges include the chief enrollment officer on that team due to the importance of the relationship that must exist (Hossler \& Kalsbeek, 2008). Participants described their roles in helping the campus leadership team, and in some cases, the governing boards, understand the implications of enrollment management decisions (Hossler \& Kalsbeek, 2008). These leaders were responsible for leading actions to stabilize enrollment, while presenting enrollment management as a campus-wide issue (Stewart, 2004). In addition, participants worked closely with particular individuals on senior management team, most frequently the chief financial officer, during the process of selecting the EMP. Below, I elaborate more on the nature and importance of these relationships within the context of leading change through coalition building (Kotter, 2012).

\section{Technology for Student Recruitment}

The extant scholarship reinforces the role that technology has come to play in enrollment management. Adoption of technology was central to this study, as each participant guided the process of selecting and adopting the EMP. Their experiences are 
not unique; many colleges and universities are integrating technology into their recruitment process (Lindbeck \& Fodrey, 2010). Participants understood that the technological component of CRM helps schools better manage and track processes, as well as increases the level of personalization in reaching prospective students (Langston \& Scheid, 2017; Pember, Owns, \& Yaghi, 2014), which is why championing new technology was so important.

Consistent with the literature, the participants' primary reason for adopting new technology was to boost enrollment, automate communication, track marketing results, and reduce costs of recruitment (Klie, 2013). As participants identified problems, they recognized flaws in work flow, processes, information management, and data collection. Processes were described as time consuming and creating additional work for their teams. These inefficiencies were largely attributed to outdated or inappropriate technology used on their campuses. Leaders in this study still struggled with manual processes, often in place because the teams did not have technology capable of automation. Often, people were doing the best they could with existing tools, however, those tools limited the potential for greater success.

Participants, perhaps by the nature of their position, all identified problems within the student recruitment operations. The problems often involved existing inefficiencies, such as hours of manual labor that could be mitigated with a new solution. They also understood that communication with prospective students needed to be improved in order to address enrollment goals. Nearly all of the problems identified linked back to the use of outdated or inappropriate technology being used for student recruitment. The problems they identified served as the impetus for change, something that prompted the exploration 
for new technology. Next, I examine how the change process unfolded by answering the research question central to this study.

\section{Establishing Urgency and Creating Coalitions}

The research question for my study was: How do enrollment management leaders at small, private, primarily undergraduate colleges describe their experience of establishing urgency and creating coalitions as they lead the selection process of adopting the EMP technology for the primary purpose of recruiting students? Below, I consider the findings from my study in light of the research question and framework that guided my research.

\section{Establishing and Maintaining Urgency}

Complacency exists within small, private, primarily undergraduate institutions (Garvin \& Roberto, 2011; Kezar, 2014). This lack of urgency to initiate change is a result of years of maintaining the status quo with no apparent crisis. A college with a healthy endowment and alternate revenue streams can survive years of minor fluctuations in enrollment with no consequence. However, failure to plan ahead and adapt to the environment eventually leads to flat or declining enrollment (Kezar, 2014). As the market for traditional aged (i.e., 18-24 years of age) students shrinks and technology advances, colleges begin to recognize their position in the market. For schools that are tuition driven, the need for students becomes urgent as the lack of enrollment impacts the budget. Participants in this study reported that previous complacency led to dire situations for some schools, resulting in the need to instill urgency for change. A lack of urgency to address enrollment challenges meant these campuses could face severe 
consequences, not unlike many other small, private colleges that are facing closure or mergers (Dennis, 2014).

Leaders removed the sources of complacency and created urgency to mobilize their team, a critical step for successfully leading change (Beer, Eisenstat, \& Spector 2011; Garvin \& Roberto, 2011; Kim \& Mauborgne, 2011). This process of creating urgency was not simple and linear, rather it involved multiple people and was ongoing throughout the early stages of change. I anticipated my participants to be the person who initially identified a problem and then established urgency, thus I was surprised to discover that in most cases the change process was already in motion. Hiring new leaders for enrollment management signaled a sense of urgency in response to flat or declining enrollment, budget cuts, self-study deadlines, and board requests for enrollment plans. These new leaders then became responsible for further assessing declining student applications and yield, identifying additional problems, and maintaining the sense of urgency to keep the change initiative moving. As they revealed root causes of enrollment problems, their own sense of urgency increased. New to the position, and often the institution, the prospect of their own professional failure motivated them to reveal their concerns and ultimate ramifications for the school if problems were not addressed. Teams on campus ultimately mobilized once they understood the real threat to the school and their own jobs.

To maintain the momentum for a continued sense of urgency and intensify it, leaders continued to inform their teams, peers, and presidents about the link between current practices and potential demise. Exposing these potential ramifications of not addressing the problems reflected the leader establishing urgency throughout the campus 
(Kotter, 2012). Inefficiencies and mistakes, such as sending the wrong information to prospective students, or not responding to interested students in a timely manner, were pointed out as problems that could be costing the institution new students. Leaders reminded stakeholders that fewer new students means declining enrollment, and declining enrollment means shrinking revenue. New leaders brought insight and knowledge of what is common practice at other schools and helped their teams understand the possibilities new processes can bring. They then raised the level of expectations for student recruitment and told their teams the former practices are no longer acceptable and needed to change, one of the strategies shared by Kotter (2012) to remove complacency.

Leaders may have come in at different stages of creating urgency, but all were responsible for employing tactics to initiate and continue that sense of urgency with others on their campus. Primary drivers for establishing urgency linked back to declining enrollment, budget cuts, not meeting revenue goals, and the need to increase flat enrollment. Removing complacency meant establishing just enough fear to mobilize the right people on campus to further change efforts. Leaders engaged key players on campus as they created urgency and began to create their coalition to lead the change effort into the next stage, which I discuss next.

\section{Creating Coalitions: No One Does It Alone}

Successfully leading change entails involving others throughout the process. This often begins as urgency is established with others on campus who have a stake in the change outcome, then continues with an effort to form a coalition to help progress the change process. The ability to form and manage relationships is always a critical skill for 
the enrollment management leader (Dennis, 2012, 2014; Henderson, 2012; Hope, 2017; Wymbs, 2016), especially when it comes to a change initiative. New leaders who need to push change quickly, like my participants, have no time to lose in building these relationships and identifying key players on campus. Recognizing campus politics is a key factor in knowing who to involve and how each can help inform and influence the change process (Bolman \& Deal, 2008; Bolman \& Gallos, 2011; Kezar, 2014; Kotter, 2012). Participants in this study demonstrated the importance of bringing in other people from varying position levels and departments across campus to instill change. The people included and involved in the process were not always referred to as a coalition specifically, but they reflect the spirit of Kotter's (2012) concept of a coalition. The process leaders used to bring in others showed how they navigated the political arenas on their individual campuses (Bolman \& Deal, 2008; Bolman \& Gallos, 2011).

Involving people with positional power (Bolman \& Deal, 2008; Kotter, 2012) helped participants overcome potential roadblocks such as technology access and funding. In adopting new technology, leaders recognized that the IT department held the power to access the main SIS, where student information ultimately resides. Adopting new technology for student recruitment meant that student information would be housed in another system and must be able to easily move to the SIS at some point. Failure to involve IT in the decision to adopt new technology could have resulted in potential delays in moving student data in a timely manner if the IT staff were not engaged in the selection and adoption processes. In this study, the level of involvement ranged from notifying IT early on, bringing them in for discussions later to ensure data could be transferred, to partnering with the head of IT to engage in discussions with potential 
vendors and evaluate demonstrations. In all cases, strong coalitions with IT were critical to the success of the change effort.

Participants also formed coalitions with other leaders who held positional power on campus (Bolman \& Deal, 2008; Kotter, 2012). For example, participants identified the CFO as a necessary member of their alliance due to their control of the budget and procurement process. Leaders partnered with their $\mathrm{CFO}$ in developing a plan to pay for the new solution, whether it was with new resources, reallocated money, or a combination of both. Participants were well aware that the price of new technology is often a large expenditure for small schools with tight budgets. Simply putting an invoice in front of the finance department with no plan or identified resources to finance it would present a significant roadblock to continuing the change process. The CFO held the purse strings and positional power that these leaders recognized as they created their coalition for the change; however, leaders also recognized other individuals who held other types of power who they needed in their change efforts.

Often in a new position, the leaders facilitating change understood that their authority based on their title and position could only accomplish so much; they needed to amass their own personal power. To do so, they rallied others who had personal power and could influence others on campus (Bolman \& Deal, 2008; Bolman \& Gallos, 2011). Participants had to be reflective and take time to understand the dynamics between people across campus to identify those with the perceived credibility to help them facilitate change. These included people who had been at the campus for a long period of time and were looked up, leaders in academic areas, and people the leaders believed may have been resistant to new technology. 
Leaders looked for key people within their own direct purview, as well as faculty and staff who represented other areas on campus, such as academic units and athletics. Once identified, leaders used several strategies to engage their support, such as asking them to serve on a formal committee, spending one-on-one time with them to understand current processes and rationale, and/or simply soliciting input and valuing their contributions. Engaging key influential people was critical for the leaders to ensure informed decisions were made and that others would not become detractors once the change was implemented. Leaders who do not seek to fully understand the current processes, rationale, and perceptions of people on campus risk making bad decisions or moving too quickly without sufficient support for later stages of change to be successful (Kotter). It appears that those in this study recognized that coalitions were necessary and worked hard to create them to advance their agenda to adopt the EMP. In addition to helping leaders gather relevant information, these individuals were vital players who could influence others to accept the change at a later stage in the process.

In summary, leaders in this study were often new to their position and school and, in some cases, their appointment was part of the process of creating urgency. For all participants, it was up to them to maintain the momentum for urgency, whether they established it or not. Many factors drove the urgency, including declining enrollment, budget cuts, missing revenue goals, and the need to increase flat enrollment. Secondary factors that reinforced the urgency were the inefficiencies in existing enrollment management processes, ineffective communication with prospective students, and the inability to obtain needed data to inform decisions. Leaders knew change was necessary and helped others see the urgency of the change by sharing the potential dire 
consequences of not making a change. For example, they reported the ramifications to the budget, data on the inefficiencies, and how the school was being represented to prospective students. As they drove urgency, the leaders intentionally involved others to help support the change initiative. Although not formally noted as a coalition, each leader identified key players on their campus and worked to get them involved. People from different areas on the campus represented positional power, personal power, expertise, credibility, or a combination of these traits that marked them as someone who could help them influence others and achieve success in the change initiative (Bolman \& Deal, 2008; Kotter, 2012). These findings give us insight into the experience these leaders had in establishing urgency and creating coalitions. As technology continues to advance, and leaders continue to face enrollment challenges, the findings of this study can be a valuable resource to help other leaders lead the early stages in the change process. Next, I share more specific recommendations about how these findings may be used in practice.

\section{Implications for Practice}

Research describes the technical components of adopting technology, and the numerical implications of it, but a gap exists in understanding the human process of leading this change (Sui, 2016). My study addresses this gap in the current literature by focusing on the human aspect of technology adoption, helping to understand how leaders championed a specific change initiative on their campus. The findings inform my recommendations for leaders who find themselves in the same situation as my participants, adopting new technology for student recruitment. Below, I share two overarching recommendations that emerged from the findings from this study: (1) assess the situation by identifying problems and (2) involve key campus constituents to mobilize 
and sustain the change initiative. The recommendations themselves align with Kotter's (2012) framework, but the details and cautions I include adapt them specifically for enrollment management leaders.

\section{Assess the Situation}

Leaders responsible for enrollment management may feel urgency and pressure to show immediate results yet must remember to take time to understand the overarching problem and root causes. This pressure may be more intense for new leaders who often inherit a dire situation, but also applies to leaders who have held their positions for some time who discover alarming trends on their own. Leaders, like those in this study, must resist the urge to make assumptions and act upon them too quickly, without truly identifying the layers of problems. If enrollment is declining, why? If new student numbers are low, what stage is showing the decline? What is happening at each stage that may contribute to the lack of progression to the next stage?

A thorough examination of current systems, teams, and processes will help identify specific problems and prioritize the manner in which each should be addressed. My findings indicate leaders, even in situations of immediate budget cuts and employee reductions, spent time to understand and further assess the situation. Leaders must replicate these types of efforts to dig deeper and then verify their discoveries by providing examples that help illustrate inefficiencies, such as the amount of time being spent to accomplish simple tasks that could be automated. Leaders should provide examples of inefficiencies and errors being made that reflect poorly on the institution. In so doing, others on campus, including those who must be engaged in the change process, understand the urgency and will be more likely to embrace the need for change. 
Once specific problems are identified, and the need for new technology is established, it may be tempting to focus on implementing the technology in isolation, forgetting that student recruitment is a campus-wide concern. Leaders must recognize the significant shift being proposed for their campus and who will be affected. Just as those in this study, I recommend that other enrollment management leaders work with key players on campus to establish urgency for change, as well as to gain support and maintain momentum.

\section{Involve Key Constituents}

The participants of my study were savvy higher education leaders who identified problems in recruiting students and then recognized the need to lead the change process for longer term success. A successful change leader knows better than to go it alone or worse, use position power and authority to force change. Whether new to the school, the position, or not, leaders should remember to lead the change itself rather than mandate and force unilateral decisions with their positional authority. A key factor in leading this change, as demonstrated by my findings, is to involve others to mobilize change. In addition to assessing the overall situation discussed in the previous section, leaders must also recognize the political arena of their school and strive to understand the channels of informal communication and influence that exist on their campus.

Using what Bolman and Deal (2008) refer to as mapping the political terrain can be a helpful tool in charting who has high levels of positional power or authority with either high or low influence, and who may have personal influence despite their position. This chart serves as a tool for the leader to begin building relationships with people on campus who can help with establishing urgency and supporting the change initiative. 
Positions that generally hold positional power on campus include the president and chief financial officer. These positions typically control institutional priorities and related resources, including the budget and/or purchasing processes. For enrollment management leaders considering new technology, IT leadership also represents those in positional power who should be brought in early on as a partner, not only to ensure technical capabilities, but also to get buy-in and support for the overall change initiative.

Enrollment management leaders should think through their complete admission process and identify who touches it, along with where they fall on the political map to determine the level of engagement needed to mobilize and support the change. Failure to bring in the right people can result in last minute hold-ups in making a final decision, or resistance to the change after the technology is in place. There is no time to lose in student recruitment. Participants in my study shared how they worked with their own directors, operations, and data managers to bring them along during the process.

Forming an official committee to drive the change initiative is another strategy that can formally show the campus who is involved. If a committee approach is used, it is important to show representation from different departments, as well as a mix of people who hold power through their position, expertise, and/or credibility on campus. Even when a formal committee or coalition is not formed, leaders know to work with the same mix of people on a more informal basis. The dynamic with each person varies depending on their role and placement on the political map. Some need reassurance from the leader and want to know they will still be employed and valued. Others include those who need to be on board with the change because they control access, resources, or hold personal 
power over others. Involving key players in the right ways leads to a true team effort, and a more likely successful change initiative.

Successfully leading the early stages of change requires a delicate balance of taking time to accurately assess the root causes of problems, mapping the political environment to determine key players, then working with them to establish urgency and get support for the initiative. These early stages are critical in setting up the later stages for success (Kotter, 2012), and thus, must be given the time and attention needed. Leaders embarking on leading change should recognize the link between my findings, the literature, and final recommendations to help them find the best path forward for their initiatives. The leader and campus will always bring unique factors to each situation, but the basics are clear: leading the change process itself is necessary and requires the champion to effectively illustrate the problem and navigate politics to engage others for support.

\section{Implications for Research}

The narrow scope of this study brings forth many opportunities for additional research. My scope was narrow both in terms of the characteristics of the participants, and the frames guiding the study. This focus was intentional, leveraging my unique access to a client base, as well as directing attention to small, private schools serving primarily traditional aged undergraduate students - the type of schools struggling the most with enrollment (Carlson et al, 2015). Although further research may go in several directions, I draw attention to five areas below.

Graduate programs. Leaders who adopt technology for specific graduate programs may describe their process differently. Small, private and primarily 
undergraduate institutions make up the primary client base for the EMP through Liaison, and I selected this population to focus on the schools cited as struggling the most. However, other EMP clients most often are specific graduate programs within a larger college or university. The leadership and staff structure for these clients is often significantly different. Many are part of a much larger system, sometimes public with different processes in place for purchasing decisions. It would be interesting to conduct a similar study with these leaders to compare findings. Is the process described differently for a smaller graduate program? Do the same triggers for urgency apply to these programs? Are the same people involved in creating a coalition? How do leaders navigate the state regulations for putting out requests for proposal (RFPs) as part of their process and when?

Institution types. Research is needed to better understand how leaders for undergraduate recruitment at public institutions, or even larger private institutions, describe their experience. State institutions are not immune to declining enrollment and budget cuts from public funding sources (Heller, 2006). Is their situation as dire and how does it translate to establishing urgency? How does a larger system with public interest, namely around procurement process, play into the change process around selecting new technology for student recruitment? Would leaders describe different challenges than those from small private schools?

Different technology. Participants all adopted the EMP within the last 3 years. This focus was based on my access to Liaison clients, but limited the study, as there are other CRM technologies for student recruitment. I hope readers can transfer the findings to their own context, but transferability would be even more likely if findings from 
studies related to other CRM are consistent with those of my study. The EMP provided a unique aspect in that in addition to the CRM it is also a marketing platform. Participants shared that this sometimes made the difference in their final decision, and also indicated the marketing capabilities is what prompted them to involve campus marketing in the process. Leaders who ended up selecting a different system may have a different experience related to those involved in their processes based on the specific functions of other systems.

Opportunities exist for researching technology adoption for other areas in higher education, such as application management, course management, and even larger changes that involve new student information systems that serve as the main system of student information. Technology for other uses, such as application management, is sometimes available at no cost to an institution, which may significantly alter the process of selection. How might a no-cost option influence the process a leader uses to drive change? Is it more likely early stages will be skipped and how does that affect adoption?

Later stages of change. Focusing on the early stages of change management meant the later stages of change models were not adequately explored. A follow-up study to focus on the later stages of change around adopting the EMP could help us seek connections between the earlier processes driving later stage success or failure. My findings revealed that the EMP had been implemented and was producing results for most but did not go into depth in addressing the steps across Kotter's (2012) other six stages. It is worth mentioning that nearly half of the participants I interviewed were no longer at the school in which they championed the selection of the EMP. This reflects the common transient nature of enrollment management leaders in higher education, but may 
make it challenging to study later stages of technology adoption, especially looking at results one, 2, or 3 years out. The introduction of new leadership later in the change process introduces another nuance that may be worth exploring as part of a study focused on later stages in Kotter's (2012) model.

Exploration of leadership. Many participants in this study were hired to "fix" the enrollment issues, and when the accomplished their goals, they moved to another institution. Others have remained at the institution and are leaders within the college. Given differences in how they approach their positions, there is an opportunity to explore participants' experiences through a leadership lens. Did participants' leadership manifest differently depending on whether they were more transient (i.e., fixers) or intended to have longevity at the institution (i.e., leaders within)? Further, what types of leaders accept these types of roles calling for immediate change management? Why are they attracted to the position and circumstances? Answers to these questions would provide valuable insight for upper level administrators, such as college presidents, who hire the enrollment management leaders to manage a turnaround process. As they seek the right leader for their campus and circumstance, these data may guide their search and selection process.

Different perspectives. Finally, research focusing on the experience others had in the change process around technology selection could round out a story from one campus. This study centered on leaders who championed the change on their campus, but did not seek out how other people involved in the process described it from their point of view. A case study project from one institution could entail interviewing multiple participants who played different roles in the process. How might their descriptions 
intersect or conflict with one another? How would each perceive their own role and others? Would multiple people identify as the champion for change? This insight may be valuable for teams to have before initiating their own search and selection of new technology.

\section{Conclusion}

This study focused on how leaders in enrollment management who had recently selected the EMP described their experience in establishing urgency and creating coalitions as part of a change management process to select technology for student recruitment. It is a challenging time for higher education enrollment, and many small schools are not meeting enrollment goals (Carlson, 2014). Enrollment is key for many colleges to survive and thrive and when enrollment declines, budgets are often cut, and resources become scarce (Carlson, 2014).

The responsibility for managing student recruitment falls to the leaders in enrollment management, and many are championing the adoption of new technology to more effectively manage operational processes, as well as to automate and personalize their outreach to prospective students, adapting to today's traditional-aged prospective student (Belkin, 2013; Fiske, 2008). Despite the evidence that new technology for student recruitment is being adopted, there is little research on the process by which any leader identifies the need for change, creates urgency, and forms coalitions to make the change happen. This study helps fill this gap in the literature by answering the research question: How do enrollment management leaders at small, private, primarily undergraduate colleges describe their experience establishing urgency and creating coalitions as they led 
the selection process to adopt the EMP technology for the primary purpose of recruiting students?

The introduction of this study drew potential similarities between Kotter's (2012) fictitious character, Fred, a penguin who recognized dangerous conditions and began to initiate the change process, to leaders in enrollment management today. Through interviews with 12 participants who were enrollment management leaders who led the change process, I discovered similarities they had to Fred in following Kotter's (2012) model for leading change. Like Fred's iceberg, enrollment provides a solid foundation on which colleges and universities can continue to survive and thrive. Declining enrollment and the resulting decrease in revenue that leads to budget shortfalls is a real issue for the future of some colleges and for those who staff those institutions. Some of the participants of this study were in dire situations of declining enrollment, budget cuts, and concerns about maintaining accreditation. These realities allowed the leaders to create urgency around the need to support student recruitment, and thus enrollment. Others identified inefficiencies in the recruitment process that would eventually inhibit success in bringing students to campus. These leaders were passionate about what they needed to do, and their facial expressions and tone helped me better interpret their own urgency, frustration in helping others understand, and eventual satisfaction in getting their point across. While maintaining a sense of urgency on their campus, the leaders describe mobilizing others to continue the change process.

Just as Fred was careful to identify the right people in the penguin colony to help guide the change process, these participants spent time learning who on their campus had positional power, expertise, credibility, and leadership (Kotter, 2012) in order to involve 
them and ensure a successful change. They shared the importance of getting buy-in from key areas on campus such as the head of IT who brought position power, expertise, and credibility to the process. Participants worked with their CFO, indicating in one case, "someone has to pay for it."

Participants also shared stories of working closely with members of their own team to help them be a part of the decision, relieve anxiety around the change, and be sure they felt valued throughout the change process. Staff on the frontline often felt threatened or nervous by the adoption of new technology, and leaders indicated they could not afford to lose any time in the transition, thus made it a priority to bring these people along.

In conclusion, the findings from this study support the recommendation for current leaders seeking new technology to truly lead the change process. Although tempting to focus on the selection and adoption of new technology itself, a savvy leader recognizes the need to also pay attention to the human process their colleagues and teams experience. Facilitating this process using change management models, such as Kotter's (2012) along with research by Kezar (2014) can help teams prepare for and embrace the needed change. Findings from this study, along with the literature and models on change can help inform leaders in enrollment management as they begin the process of selecting new technology to enhance their recruitment efforts. 


\section{REFERENCES}

Anderson, N. (2015, March 4). College enrollment: Trouble signs. Washington Post. Retrieved from https://www.washingtonpost.com/news/gradepoint/wp/2015/03/04/college-enrollment-trouble-signs/?utm_term=.5562c8ec366a

Astin, A., \& Astin, H. (2000). Leadership reconsidered: Engaging in higher education in social change. Battle Creek, MI: W. K. Kellogg Foundation.

Belkin, D. (2013, Nov. 11). U.S. private colleges face enrollment decline; Schools respond with cutbacks, mergers and new recruitment strategies. Wall Street Journal. Retrieved from https://www.wsj.com/articles/us-private-colleges-faceenrollment-decline-1383957321

Bejou, D. (2005). Treating students like customers. Business Education, 4(3), 44-47.

Berman, J. (2015, March 28). Why more U.S. colleges will go under in the next few years. MarketWatch. Retrieved from http://www.marketwatch.com/story/whymore-private-colleges-are-closing-2015-03-25

Bolman, L. B., \& Deal, T. E. (2008). Reframing organizations: Artistry, choice, and leadership (4th ed.). San Francisco, CA: Jossey-Bass.

Bolman, L. B., \& Gallos, J. V. (2011). Reframing academic leadership. San Francisco, CA: Jossey-Bass.

Bontrager, B., \& Green, T. (2015). Strategic Enrollment Planning. In D. Hossler \& B. Bontrager (Eds.), Handbook of strategic enrollment management (pp. 531-548). San Francisco, CA: Jossey-Bass. 
Bowen, H. (1980). The costs of higher education: How much do colleges and universities spend per student and how much should then spend? San Francisco, CA: JosseyBass.

Blumenstyk, G. (2015, July 1). How can you tell when a college is circling the drain? The Chronicle of Higher Education. Retrieved from https://www.chronicle.com/article/How-Can-You-Tell-When-a/231285

Bush, T. (2003). Theories of educational leadership and management (3rd ed.). Thousand Oaks, CA: Sage.

Carlson, S. (2014, Oct. 13). Goals for enrollment and tuition revenue elude many colleges. The Chronicle of Higher Education, 61(1), 1-1.

Carlson, S., Blumenstyk, G., \& Thomason, A. (2013, Oct. 15). Enrollment: A moving target for many colleges. The Chronicle of Higher Education, 60(7), A2-A5.

Creswell, J. W. (2009). Research design: Qualitative, quantitative, and mixed methods approaches (3rd ed.). Thousand Oaks, CA: Sage.

Creswell, J. W. (2007). Qualitative inquiry and research design: Choosing among five traditions (2nd ed.). Thousand Oaks, CA: Sage.

Davis, J. R. (2003). Learning to lead: A handbook for postsecondary administrators. New York, NY: Rowman and Littlefield.

Dalton, B., \& Somers, P. (2015). The "Hail Mary" touchdown: A study of how football became an enrollment strategy for small private colleges. Strategic Enrollment Management Quarterly, 2(4), 294-306.

Dasgupta, S., Symes, K., \& Hyman, L. (2015). Leading change: Curriculum reform in graduate education in the biomedical sciences. Biochemistry and Molecular 
Biology Education, 43(2), 126-132.

Dennis, M. J. (2014). Who is responsible for managing enrollment? Dean and Provost, $16(2), 1,4-5$.

Dennis, M. J. (2012). Anticipatory enrollment management: Another level of enrollment management. College and University, 88(1), 10-16.

Eisenstat, R. A., Spector, B., \& Beer, M. (1990). Why change programs don't produce change. Harvard Business Review. Retrieved from https://hbr.org/1990/11/whychange-programs-dont-produce-change

Fiske, E. B. (2008, September). How college admissions came to be hawked in the marketplace. Chronicle of Higher Education, 55(5). Retrieved from http://www.chronicle.com/article/How-College-Admissions-Came-to/25250

French, J., \& Raven, B. (2005). The basis of social power. In J. Shafritz \& J. Ott \& Y. Jang (Eds.), Classics of organization theory (6th ed.), (pp. 48-60). Belmont, CA: Thomas Wadsworth.

Freidrich, A. (2015). Drop in enrollment means financial trouble for MnSCU. MPR. Retrieved from http://www.mprnews.org/story/2015/03/17/mnscu-enrollment-drop

Garvin, D. A., \& Roberto, M. A. (2005). Change through persuasion. Harvard Business Review. Retrieved from https://hbr.org/2005/02/change-through-persuasion

Guilbault, M. (2016). Students as customers in higher education: Reframing the debate. Journal of Marketing for Higher Education, 26(2), 132-142.

Heller, D. E. (2006). State support of higher education: Past, present, and future. In D. Priest, \& E. St. John (Eds.), Privatization and public universities (pp. 11-37). 
Bloomington, IN: Indiana University Press.

Henderson, S. E. (2012). The community of SEM. In B. Bontrager, D., Ingersoll, \& R. Ingersoll (Eds.), Strategic enrollment management: Transforming higher education (pp. 97-109). Washington, DC: American Association of Collegiate Registrars and Admissions Officers.

Hillman, N. W. (2011). Tuition discounting for revenue management. Research in Higher Education, 53(3), 263-281.

Hope J. (2017). Create an enrollment management structure to support recruitment, retention goals. Enrollment Management Report, 20(12), 1-5.

Hossler, D. (2015). Origins of strategic enrollment management. In D. Hossler \& B. Bontrager (Eds.), Handbook of strategic enrollment management (pp. 3-17). San Francisco, CA: Jossey-Bass.

Hossler, D., \& Bontrager, B. (2015). Handbook of strategic enrollment management. San Francisco, CA: Jossey-Bass.

Hossler, D., \& Kalsbeek, D. (2008). Enrollment management and managing enrollment: Setting the context for dialogue. College and University, 83(4), 2-4, 6-9.

Hossler, D., Kalsbeek, D., \& Bontrager, B. (2015). Successful strategic management organizations. In D. Hossler \& B. Bontrager (Eds.), Handbook of strategic enrollment management (pp. 31-46). San Francisco, CA: Jossey-Bass.

Islam, M. S., \& Al Mamun, M. A. (2016). Perception of management on outcomes of human resource information system (HRIS). International Journal of Business and Social Research, 6(2), 29-37.

Kezar, A. (2014). How colleges change. Understanding, leading, and enacting change. 
New York, NY: Routledge.

Kim, W. C., \& Mauborgne, R. (2011). Tipping point leadership. In Harvard Business Review's 10 Must Reads on Change Management (pp. 79-98). Boston, MA: Harvard Business School Publishing.

Klie, L. (2013, September). Schools need to rethink their CRM approaches. Customer Relationship Management Magazine, 17(9). Retrieved from http://www.destinationcrm.com/Articles/Editorial/Magazine-Features/SchoolsNeed-to-Rethink-Their-CRM-Approaches-91513.aspx

Kotter, J. (2012). Leading change. Boston, MA: Harvard Business Review Press.

Kotter, J., \& Rathgeber, H. (2005). Our iceberg is melting. New York, NY: St. Martin's Press.

Levenstein, N. (2012). The reality, direction and future of computerized publications. Journal of College Admission, 214, 86-89.

Langston, R., \& Loreto, D. (2017). Seamless integration of predictive analytics and CRM within an undergraduate admissions recruitment and marketing plan. Strategic Enrollment Management Quarterly, 4(4), 161-172.

Langston, R., \& Scheid, J. (2014). Strategic enrollment management in the age of austerity and changing demographics: Managing recruitment, leveraging, revenue, and access in challenging economic times. Strategic Enrollment Management Quarterly, 2(3), 191-210.

Langston, R., Wyant, R., \& Scheid, J. (2016). Strategic enrollment management for chief 
enrollment officers: Practical use of statistical and mathematical data in forecasting first year and transfer college enrollment. Strategic Enrollment Management Quarterly, 4(2), 74-89.

Lenhart, A. (2015). Teens, social media, \& technology overview 2015. Pew Research Center. Retrieved from http://www.pewinternet.org/2015/04/09/teens-social-media-technology-2015/

Levine, A., \& Dean, D. R. (2013). It's only technology if it happens after you were born. Journal of College Admission, 220, 6-12.

Lewison, D. M., \& Hawes, J. M. (2007). Student target marketing strategies for universities. Journal of College Admission, 196, 14-19.

Lincoln, Y. S., \& Guba, E. G. (1985). Naturalistic inquiry. Beverly Hills, CA: Sage. Lindbeck, R., \& Fodrey, B. (2010). Using technology in undergraduate admissions: A student perspective. The Journal of College Admission, 208, 10-17.

Lindbeck, R., \& Fodrey, B. (2009). Using technology in undergraduate admissions: Current practices and future plans. The Journal of College Admission, 204, 25-30.

Lingrell, S. (2014). Enrollment “management” isn't good enough anymore! Enrollment leadership for a campus transformation. Strategic Enrollment Management Quarterly, 1(4), 242-250.

Marshall, C., \& Rossman, G. B. (1999). Designing qualitative research. Thousand Oaks, CA: Sage.

Merriam, S. B., \& Tisdell, E. J. (2016). Qualitative research: A guide to design and implementation. San Francisco, CA: Jossey-Bass.

Meyerson, D. E. (2011). Radical change, the quiet way. In Harvard Business 
Review's 10 Must Reads on Change Management (pp. 59-78). Boston, MA: Harvard Business School Publishing.

National Student Clearinghouse (2015). Current term enrollment estimates: Fall 2015. Retrieved from https://nscresearchcenter.org/currenttermenrollmentestimate-fall2015/

Oluseye, O. O., Tairat, B. T., \& Emmanuel, J. O. (2014). Customer relationship management approach and student satisfaction in higher education. Journal of Competitiveness, 6(3), 49-62.

Pember, E., Owens, A., \& Yaghi, S. (2014). Customer relationship management: A case study from a metropolitan campus of a regional university. Journal of Higher Education Policy and Management, 36(2), 117-128.

Pfeffer, J. (2005). Understanding the role of power in decision-making. In J. Shafritz, J. Ott, \& Y. Jang (Eds.), Classics of organization theory (6th ed.) (p. 48-60). Belmont, CA: Thomas Wadsworth.

Priest, D., \& St. John, E. (2006). Privatization and public universities. Bloomington, IN: Indiana University Press.

Rahim, M. A., (2011). Managing conflict in organizations. New Brunswick, NJ: Transaction.

Rigo, G. E., Pedron, C. D., Caldeira, M., \& Silva de Araujo, C. C. (2016). CRM adoption in a higher education institution. Journal of Information Systems and Technology Management, 13(1), 45-60.

Schultz, S. A., \& Lucido, J. A. (2011). What enrollment management structures reveal about institutional priorities. Enrollment Management Journal, 5(4), 12-44. 
Seeman, E. D., \& O’Hara, M. (2006). Customer relationship management in higher education. Using information technology systems to improve the student-school relationship. Campus-Wide Information Systems, 23(1), 24-34.

Seidman, I. (2006). Interviewing as qualitative research: A guide for researchers in education and the social sciences. New York, NY: Teachers College Press.

Siu, N. (2016). Customer relationship management and recent developments. Administrative Sciences, 6(3), 6-7.

Smith, J. A., Larkin, M., \& Flowers, P. (2009). Interpretative phenomenological analysis: Theory, method and research. London, England: Sage.

Smith, J. A., \& Osborn, M. (2015). Interpretative phenomenological analysis. In J. Smith (Ed.) Qualitative psychology: A practical guide to research methods (3rd ed.), (pp. 25-52). Thousand Oaks, CA: Sage.

Stewart, G. (2004). Defining the enrollment manager: Visionary, facilitator, collaborator. Journal of College Admission, 183, 21-25.

Stripling, J. (2015, June 25). Sweet Briar's activists turn to the sober work of governing. The Chronicle of Higher Education, 40, A9.

Sutton, H. (2016). Use strategic enrollment planning to prepare your institution for today's reality. Enrollment Management Report, 20(7), 1, 4-5.

Thomason, A. (2015, July 20). Moody's upgrades higher ed's outlook from "negative" to "stable." The Chronicle of Higher Education. Retrieved from https://www .chronicle.com/blogs/ticker/moodys-upgrades-higher-eds-outlookfrom-negative-to-stable/102213 
Wootton, W. (2016, June 8). The real reason small colleges fail. The Chronicle of Higher Education, 39, A48.

Wymbs, C. (2016). Make better use of data across the student lifecycle. Enrollment Management Report, 20(9), 8-8.

Yin, R. (2014). Case study research design and methods. (5th ed). Thousand Oaks, CA: Sage. 


\section{APPENDIX A: RECRUITMENT EMAIL}

To: $<$ Name $>$

From: Suzanne Sharp

RE: Request for participation

Date: September 1, 2017

Hello $<$ Name $>$,

This email is to ask for your participation in my dissertation research. I am working on completing a doctorate of education in leadership and policy analysis at the University of Missouri. The purpose of my study is to understand the experience enrollment management leaders had in leading the process of adopting technology for student recruitment, specifically, the adoption of the Enrollment Marketing Platform (EMP). You are under no obligation, direct or implied, to participate and participation is completely voluntary.

I will be inviting all enrollment management leaders from small, private, primarily undergraduate institutions who have adopted the EMP since January of 2015 to participate in my research. Participation will entail one individual interview between September 15, 2017 and October 15, 2017. Interviews will be conducted via GoToMeeting to allow for face-to-face interviews. Participants will need to have a computer and internet access for the interview, and a camera is preferred. The total time commitment for you should not exceed 60-90 minutes.

The content of the interviews will be confidential. The audio for each interview will be recorded, with your permission, and your identity will be kept confidential. Pseudonyms for participants and colleges will be used in all publications and presentations. I will code the participants' information for transcription, and only I will have access to the recorded data. After the data have been transcribed, you will have the opportunity to review for accuracy. Only approved transcriptions of the data will be used for analysis and included in the final report.

As a result of this research, I hope to better understand your personal leadership experience in adopting the EMP, especially around how you created urgency and formed coalitions to get to a decision point.

For those who consent to interview, I will send further details and contact you to schedule an interview with you to take place during the stated time period. Before we start the interview, I will review the study with you. 
Please let me know of your willingness to participate by September 10, 2017 by responding to this email.

Thank you. 


\section{APPENDIX B: CONFIRMATION EMAIL}

To: $<$ Name $>$

From: Suzanne Sharp

RE: Confirmation of participation

Date: TBD

Hello $<$ Name $>$,

Thank you for agreeing to participate in my doctoral research. I have attached a copy of the informed consent document I shared with our Institutional Review Board. The information in this document should answer questions about the research and outline your rights as a participant.

Also attached is the short demographic questionnaire I referenced in my previous email. Please take a few minutes to answer these questions. This information will verify you meet the criteria to participate as well as help me prepare for our interview.

I'd also like to get our interview time scheduled. Please let me know if any of the following time slots will work for you:

\section{INSERT DATES AND TIMES}

Once we have a date and time confirmed, I will send you a confirmation email with the GoToMeeting link. Please ensure your computer has a camera and can run GoToMeeting. You will also need to be connected to the internet.

If you have any questions regarding the questionnaire, the informed consent document, or GoToMeeting, please do not hesitate to contact me at ssbb7@mail.missouri.edu or 573268-6777.

I look forward to our meeting! 


\section{APPENDIX C: IRB LETTER AND INFORMED CONSENT}

RESEARCHER: Suzanne Sharp ssbb7@,mail.missouri.edu

573-268-6777

PROJECT TITLE: Championing Change for College Recruitment: Leader Experiences in Managing Change for New Technology Adoption

\section{YOU ARE BEING ASKED TO VOLUNTEER TO PARTICIPATE IN A RESEARCH} STUDY

- You are being asked to participate in a research study. This research is being conducted for dissertation research at the University of Missouri. The purpose of the study is to understand the experiences of enrollment management leaders in leading change to adopt new technology for student recruitment. When you are invited to participate in research, you have the right to be informed about the study procedures so that you can decide whether you want to consent to participation. This form may contain words that you do not know. Please ask the researcher to explain any words or information that you do not understand.

- Your participation is voluntary. If you choose to participate in the study you are free to not answer any question. You do not have to be in the study if you do not want to. You may refuse to be in the study and nothing will happen. If you do not want to continue to be in the study, you may stop at any time without penalty or loss of benefits to which you are otherwise entitled.

\section{HOW LONG WILL I BE IN THE STUDY?}

- The time commitment for you should not exceed 90 minutes. Interviews will be conducted during the time period September 15, 2017 - October 15, 2017.

- Follow-up, including your approval of the transcribed interview, use of quotes, and additional questions will not be requested past November 15, 2017. You are not required to approve the transcript or be available for additional questions.

\section{WHAT AM I BEING ASKED TO DO?}

- For the study, I am asking to meet with you for one interview to discuss your description and experience of adopting the EMP. There are no right or wrong answers and I am interested only in your perceptions and experiences. The interview should not exceed more than 90 minutes. In some cases, I may request a follow-up interview with you, which you are free to decline. The interviews will be conducted via GoToMeeting with the cameras on. I am requesting permission to record the audio portion of the interview so that I can accurately capture your comments and provide you with my full attention during the interview itself.

HOW MANY PEOPLE WILL BE IN THE STUDY? 
- I will be inviting approximately 17 enrollment management leaders to participate.

\section{WHAT ARE THE BENEFITS OF BEING IN THE STUDY?}

- There will be no direct benefit to you for your participation in this study. However, the information obtained from this study may lead to greater understanding of the experience of enrollment management leaders as they navigate politics on a college campus to influence change.

\section{WHAT ARE THE RISKS OF BEING IN THE STUDY?}

- Your participation in this study is not expected to cause you any risks greater than those encountered in everyday life. You may decline to answer any or all questions and you may terminate your involvement at any time.

- There are no anticipated circumstances under which your participation will be terminated by the investigator. There are no adverse consequences (physical, social, economic, legal, or psychological) of your decision to withdraw from the research.

\section{CONFIDENTIALITY}

- Your identity and participation will remain confidential. Confidentiality pertains to confidentiality of data. I will make every effort to preserve your confidentiality. At the beginning of our interview I will ask you to select a pseudonym for your name and your institution. Your name will not be shared with anyone and records will be coded so your name does not appear on any data.

- Information from this research will be used solely for the purpose of this study and any publications for academic purposes that may result from this study. Participants' responses will remain confidential and separate from any identifying information. Interviews will be recorded using and assigned a code using no identifying information. I will code the participants' information for transcription, and only I will have access to the recorded data.

- Your identity will not be disclosed in the reporting of results. I will not list any names of participants or the college in my dissertation or any future publications of this study without explicit consent. Collected data will be kept secure on a password-protected drive and after the data has been transcribed and accepted in the final dissertation, I will destroy the tapes. Only approved transcriptions of the data will be used for analysis.

\section{PRIVACY}

- Participants have a right to privacy. I will protect information you share and limit access to others as outlined. No one will have access to the information you share other than me as the researcher. Interview data will be used to analyze for themes and patterns rather than individual statements. In the event a quote is used any identifying information will be 
removed. Participants will be able to approve the summary data analysis for accuracy.

- If you do not understand what is written above, please contact me, the researcher, directly atssbb7@mail.missouri.edu or 573-268-6777.

WILL THE RESEARCHER TELL ME IF SOMETHING CHANGES IN THE STUDY?

- You will be informed of any new information discovered during the course of this study that might influence your health, welfare, or willingness to be in this study. Significant new findings during the course of the research, which may relate to your willingness to continue participation, are unlikely.

WHERE CAN I LEARN MORE ABOUT PARTICIPATING IN RESEARCH?

- The Campus Institutional Review Board offers educational opportunities to research participants, prospective participants, or their communities to enhance their understanding of research involving human participants, the IRB process, the responsibilities of the investigator and the IRB. You may access the Campus IRB website to learn more about the human subject research process at http://www.research.missouri.edu/cirb/index.htm.

WHO DO I CONTACT IF I HAVE QUESTIONS, CONCERNS, OR COMPLAINTS?

- Please contact me (Suzanne Sharp) directly at ssbb7@,mail.missouri.edu or 573-268-6777.

- You may also contact my doctoral committee advisor, Dr. Jennifer Hart at jhart@missouri.edu or 573-884-1402.

- You may also contact the University of Missouri Institutional Review Board at 573-882-9585.

WHO DO I CONTACT IF I HAVE QUESTIONS ABOUT MY RIGHTS, CONCERNS, COMPLAINTS OR COMMENTS ABOUT THE RESEARCH?

- You may contact the Campus Institutional Review Board if you have questions about your rights, concerns, complaints or comments as a research participant. You can contact the Campus Institutional Review Board directly by telephone or email to voice or solicit any concerns, questions, input or complaints about the research study.

Campus Institutional Review Board

483 McReynolds Hall

Columbia, MO 65211

573-882-9585

E-Mail: umcresearchcirb@missouri.edu

Website: http://www.research.missouri.edu/cirb/index.htm

WILL I GET A COPY OF THIS FORM TO TAKE WITH ME?

- A copy of this letter will be emailed to you before you participate in the research. 


\section{APPENDIX D: INTERVIEW QUESTIONS}

1. Tell me a little bit about you, your background, current position and responsibilities at $\mathrm{X}$ college/university. What is the structure/hierarchy of your college/university and where do you fit in?

2. Describe how you were prompted to begin exploring new technology for recruitment.

3. Why were you the person who led this process? How did the responsibility fall to you?

4. Have you been involved with the selection of technology prior to this? When? What was the technology?

5. What was the process for exploring and making a final decision?

6. Who was involved in this process? What role did each person play in the process?

7. How long did the process take? Why did it take that long/why was it so quick?

8. How was the final decision made? 
VITA

Suzanne Sharp grew up in Minnesota and attended St. Cloud State University for her undergraduate degree, where she discovered the world of higher education administration. She became a resident assistant and also completed an internship in the admissions office while majoring in communication studies. She then held a graduate assistantship as a hall director at Central Missouri State University (now University of Central Missouri) to begin her master's program in student personnel administration. During the course of her graduate work, Suzanne also worked at Central Methodist College (now Central Methodist University), Westminster College, and the University of Missouri, holding positions in residential life, admissions, and student affairs.

In 2004 Suzanne began working at Stephens College to build enrollment for their graduate and continuing studies program. Over nearly 10 years she oversaw graduate and adult enrollment as executive director and dean, served as vice president for innovation and new initiatives, and finally as vice president for enrollment management. In 2014 Suzanne began working for Spectrum, later purchased by Liaison International, where she currently serves as the executive director for enrollment management consulting and works with current and prospective clients to develop effective recruitment strategies. 